\title{
Accurate ab initio Quartic Force Fields of Cyclic and Bent $\mathrm{HC}_{2} \mathrm{~N}$ Isomers
}

\author{
Natalia Inostroza ${ }^{1, \mathrm{a}}$, Xinchuan Huang ${ }^{2, \mathrm{~b}}$ and Timothy J. Lee $\mathrm{e}^{3, \mathrm{c}}$ \\ ${ }^{1}$ NASA Ames Research Center, Mail Stop 245-6, Moffett Field, California 94035-1000, USA \\ ${ }^{2}$ SETI Institute, 189 Bernardo Ave, Suite 100, Mountain View, CA 94043, USA \\ ${ }^{3}$ NASA Ames Research Center, Mail Stop 245-1, Moffett Field, California 94035-1000, USA
}

\begin{abstract}
Highly correlated $a b$ initio quartic force field (QFFs) are used to calculate the equilibrium structures and predict the spectroscopic parameters of three $\mathrm{HC}_{2} \mathrm{~N}$ isomers. Specifically, the ground state quasilinear triplet and the lowest cyclic and bent singlet isomers are included in the present study. Extensive treatment of correlation effects were included using the singles and doubles coupled-cluster method that includes a perturbational estimate of the effects of connected triple excitations, denoted $\operatorname{CCSD}(\mathrm{T})$. Dunning's correlation-consistent basis sets cc-pVXZ, $X=3,4,5$, were used, and a three-point formula for extrapolation to the one-particle basis set limit was used. Core-correlation and scalar relativistic corrections were also included to yield highly accurate QFFs. The QFFs were used together with second-order perturbation theory (with proper treatment of Fermi resonances) and variational methods to solve the nuclear Schrödinger equation. The quasilinear nature of the triplet isomer is problematic, and it is concluded that a QFF is not adequate to describe properly all of the fundamental vibrational frequencies and spectroscopic constants (though some constants not dependent on the bending motion are well reproduced by perturbation theory). On the other hand, this procedure (a QFF together with either perturbation theory or variational methods) leads to highly accurate fundamental vibrational frequencies and spectroscopic constants for the cyclic and bent singlet isomers of $\mathrm{HC}_{2} \mathrm{~N}$. All three isomers possess significant dipole moments, 3.05D, 3.06D, and 1.71D, for the quasilinear triplet, the cyclic singlet, and the bent singlet isomers, respectively. It is concluded that the spectroscopic constants determined for the cyclic and bent singlet isomers are the most accurate available, and it is hoped that these will be useful in the interpretation of high-resolution astronomical observations or laboratory experiments.
\end{abstract}

a) Permanent address:Universidad de Chile, Facultad de ciencias, Departamento de Física, Las palmeras 3425, Nuñoa, Santiago, Chile. Electronic email: Natalia.p.Inostrozapino@nasa.gov, Natalia.Inostrozapino@gmail.com.

b) Electronic mail: Xinchuan.Huang-1@,nasa.gov

c) Author to whom correspondence should be addressed: Electronic mail:Timothy.J.Lee@,nasa.gov. 


\section{INTRODUCTION}

During the last 40 years a number of polyenes, in particular cyanopolyenes $\left(\mathrm{HC}_{3} \mathrm{~N}, \mathrm{HCN}\right.$, $\left.\mathrm{HC}_{7} \mathrm{~N}, \mathrm{HC}_{9} \mathrm{~N}, \mathrm{HC}_{11} \mathrm{~N}, \mathrm{HC}_{4} \mathrm{~N}\right)^{1-7}$ have been detected in interstellar space by radio telescopes. This class of molecule may play an important role in astronomy and interstellar chemistry due to their astrophysical abundance and rather large dipole moments.

One of the cyanopolyenes, the molecule $\mathrm{HC}_{2} \mathrm{~N}$ can be present as many isomers with different geometries such as a linear, bent, or cyclic structure in either a singlet or triplet electronic state. While the molecule that was detected in $1991^{8}$ has a bent structure and a triplet electronic state, there is reason to expect that other isomers will be low lying. For example, the isoelectronic molecule, $\mathrm{C}_{3} \mathrm{H}_{2}$, possesses a cyclic singlet ground state (cyclopropenylidene) ${ }^{9,10}$, and has been observed in many astronomical observations ${ }^{11-13}$. Further, cyclopropenylidene is essentially the smallest aromatic molecule, and thus the singlet, cyclic $\mathrm{HC}_{2} \mathrm{~N}$ molecule is the smallest aromatic molecule that contains a nitrogen atom. Thus one can make the follow analogy: cyclopropenylidene is thought to be formed by dissociative recombination of an electron with cyclic $\mathrm{C}_{3} \mathrm{H}_{3}{ }^{+}$, which also commonly exist in two forms - cyclopropenyl cation and propargyl cation ${ }^{14}$. Hence the cyclic isomer of $\mathrm{HC}_{2} \mathrm{~N}$ could be formed by the same pathway - that is due to dissociative recombination of an electron to cyclic $\mathrm{H}_{2} \mathrm{C}_{2} \mathrm{~N}^{+}$(which is the lowest energy form).

In addition, the cyclic $\mathrm{HC}_{2} \mathrm{~N}$ isomer was found to be an intermediate between the interconversion of the bent $\mathrm{HCCN}$ and the unknown bent $\mathrm{HCNC}$ on the hypersurface of neutral, anionic and cationic species where the barriers are feasible ${ }^{15}$. Thus the cyclic singlet isomer seems to be a good candidate for astrophysical detection, considering these various possible formation pathways and its large dipole moment. The purpose of our study is to provide accurate spectroscopic constants for the low-lying singlet isomers of cyclic and bent $\mathrm{HC}_{2} \mathrm{~N}$ which may be used to assign spectra from either high-resolution astronomical observations or laboratory experiments, and we include the quasilinear triplet ground state for comparison.

Previously, $\mathrm{HC}_{2} \mathrm{~N}$ has been the subject of many experimental and theoretical analyses. The main focus has been to determine the molecular structure of the ground state, that is, whether it is linear, quasilinear, or bent.

Early experiments by Dendramis and Leroi using matrix infrared (IR) and ultraviolet (UV) spectroscopy concluded the radical to be linear by performing a normal mode analysis ${ }^{16}$. Additionally, 
Saito et. $a 1^{17}$ found a triplet linear ground state in the absence of $\mathrm{K}$ type satellite transitions, and these results were in agreement with earlier electron paramagnetic resonance (EPR) ${ }^{18-21}$ studies. However, in 1990 Brown et. al slightly modified their previous experimental conclusion based on a microwave study, suggesting a quasilinear structure instead of a strict linear one ${ }^{22}$. More experimental evidence for the quasilinearity of cyanocarbene came from analysis of high-resolution rotational ${ }^{23}$ and vibrational $^{24-29}$ spectra. McCarthy and co-workers ${ }^{23}$ estimated the transition energies from relative intensity measurements in the microwave region. From that analysis they concluded that the $\mathrm{HC}_{2} \mathrm{~N}$ radical is not a normal bent or a well-behaved linear molecule. In addition, Morter et al. ${ }^{24}$ through the high resolution infrared spectrum of $\mathrm{HC}_{2} \mathrm{~N}$ in the $\mathrm{CH}$ stretching region were able to deduce a very floppy HCX bending potential, which is characteristic of a quasilinear molecule. The quasilinear nature of the triplet ground state of $\mathrm{HC}_{2} \mathrm{~N}$ has subsequently been studied further via photoelectron spectroscopy. ${ }^{30}$

Theoretical studies supported either a linear or quasilinear structure, where the difference between those two results was dependent on the level of theory. In 1987, Rice and Schaefer performed a multireference singles and doubles configuration interaction (MRSDCI) study on the triplet $\mathrm{HC}_{2} \mathrm{~N}$, reporting that the bent-linear separation is only $0.8 \mathrm{kcal} / \mathrm{mol}^{31}$. Essentially the same value was obtained by Seidl and Schaefer ${ }^{32}$ in 1992 using the coupled-cluster single and double excitation method that includes a perturbational estimate of connected triple excitations $[\operatorname{CCSD}(\mathrm{T})]^{33}$. Malmqvist et al. used the complete-active-space self-consistent field (CASSCF) method ${ }^{34}$ together with a polarized double zeta basis set (DZP) and found that the triplet cyanomethylene is bent ${ }^{35}$ and more recently, Koput et al. ${ }^{36}$ reported that the equilibrium structure of the molecule was found to be planar and bent using the coupled-cluster method, $\operatorname{RCCSD}(\mathrm{T})$, and basis sets cc-pVnZ (from double throughquintuple quality). In 2002, Nimlos et al. ${ }^{30}$ performed $a b$ intio and density functional theory calculations, mapping out the bending region and confirming the quasilinear nature of the ground state triplet.

Considering the results of the previous experimental and theoretical studies, there is consensus that the ground electronic state is a bent triplet with a quasilinear bending mode. However, as discussed above, there is reason to expect that in astrophysical environments other isomers will exist, and to our knowledge there is no experimental evidence for these. Aoki et al. ${ }^{37}$ have studied various singlet and triplet isomers of $\mathrm{HC}_{2} \mathrm{~N}$ and were able to estimate the relative energies using the QCISD(T) method with the D95** basis set plus single point energy calculations at the SDCI+Q level 
of theory with the general contraction scheme of the ANO basis set. Therein he found that the most stable singlet species corresponds to the cyclic isomer $(7.7 \mathrm{kcal} / \mathrm{mol}$ above the ground state quasilinear triplet structure), followed by the bent singlet isomer at $13.8 \mathrm{kcal} / \mathrm{mol}$ above the quasilinear triplet cyanomethylene. In 2002, Park and Lee ${ }^{38}$ studied isomers of $\mathrm{HC}_{2} \mathrm{~N}$, but limited themselves to triplet electronic states. More recently, Kassaee et al. ${ }^{39}$ studied the singlet and triplet isomers of $\mathrm{HC}_{2} \mathrm{~N}$ and found that the only low energy isomers are the ground state quasilinear triplet, the cyclic singlet, and the bent singlet HCCN isomer. Specifically, using G2 theory they found that the cyclic singlet was $5.0 \mathrm{kcal} / \mathrm{mol}$ higher in energy that the ground state triplet, and the bent singlet isomer is $7.6 \mathrm{kcal} / \mathrm{mol}$ higher than the ground state triplet. All other isomers were at least $32 \mathrm{kcal} / \mathrm{mol} \mathrm{higher} \mathrm{in} \mathrm{energy} \mathrm{than}$ the ground state triplet.

The present work was undertaken with the aim of computing high-quality ab initio quartic force fields (QFFs) and spectroscopic constants for the cyclic and bent structures of cyanocarbene in the ${ }^{1} \mathrm{~A}^{\prime}$ electronic state. We also compute a high-quality QFF for the ${ }^{3} \mathrm{~A}^{\prime}$ ground state bent structure and all of these possess $\mathrm{C}_{\mathrm{s}}$ symmetry. The quasilinear triplet ground state is included for two reasons: 1) to determine how well a QFF performs for a quasilinear species, and 2) to compare with the bent singlet isomer and determine whether it also has a quasilinear nature. We used the CCSD(T) method to compute highly accurate spectroscopic constants and vibrational fundamental frequencies for these isomers. To our knowledge, ab initio QFFs have never been reported for any of these electronic states of $\mathrm{HC}_{2} \mathrm{~N}$. The theoretical approach is described in the next section, followed by results, discussion and conclusions.

\section{THEORY AND COMPUTATIONAL DETAILS}

For the two singlet electronic states, we used the closed-shell $\operatorname{CCSD}(\mathrm{T})$ method that is based on restricted Hartree-Fock (RHF) molecular orbitals ${ }^{40-42}$. For the triplet electronic state, we used the spinrestricted coupled-cluster method including single and double excitations and a perturbational correction due to connected triple excitations, $\operatorname{RCCSD}(T)^{43,44}$ based on RHF molecular orbitals as a reference wave function. All electronic structure calculations were performed with the MOLPRO 2008.1 program $^{45}$. The one-particle basis sets employed are the correlation-consistent polarized valence basis sets, cc-pVnZ ${ }^{46}$, where $\mathrm{n}=\mathrm{T}, \mathrm{Q}$, and 5 .

The QFFs of cyanocarbene were calculated using the procedure outlined in Ref. 47. The reference geometry in this case was obtained by adding a core-correlation correction to the structure optimized at the CCSD(T)/cc-pV5Z or RCCSD(T)/cc-pV5Z level of theory. As outlined in Ref. 47, a 
grid of points is constructed about the reference geometry and all electronic structure calculations are performed for each of these points. For each point, we include a scalar relativity correction, by means of the second order Douglas-Kroll-Hess method ${ }^{48-50}$, and a core correlation correction, estimated using the Martin-Taylor core-correlation basis set $^{51}$. The coupled cluster energies were extrapolated to the one-particle basis set limit using a two-point (1) and three-point (2) extrapolation formula ${ }^{52,53}$. Both formulas were tested in order to determine the best QFFs. The exact formulas we used are given here:

$$
\begin{gathered}
E(l)=E(\infty)+B(l)^{-3} \\
E(l)=E(\infty)+B(l+1 / 2)^{-4}+C(l+1 / 2)^{-6}
\end{gathered}
$$

where $l$ is the highest angular momentum used in the one particle basis set. The electronic energies of all points that have been used to fit the QFFs were computed in the same way, and the formula is given here:

$$
E(l)=E(T Q 5)+E(r e l-n r e l)+E(m t c c-n m t c c)
$$

where $\mathrm{E}_{(\mathrm{TQ} 5)}$ represents $\operatorname{CCSD}(\mathrm{T})$ or $\mathrm{RCCSD}(\mathrm{T})$ energies extrapolated to the one-particle basis set limit, the second term represents the contribution due to scalar relativistic effects, and the last term represents the core-correlation correction.

The grids for each electronic state consisted of 743 of distinct geometries and these were used to fit our best QFFs. These QFFs produced a new reference geometry called the "real minima," or in other words, the geometry where the gradient terms are zero. As described in the procedure outlined in Ref. 47, the QFFs are then transformed to the "real minima" and these represent the final QFFs. The sum of the squared residuals from the least squares fitting procedure were $1.3^{*} 10^{-16} \mathrm{a} . \mathrm{u}^{2}$ for the 743 bent-triplet geometries, $1.2 * 10^{-16}$ for the bent-singlet and $1.0^{*} 10^{-16}$ a. $\mathrm{u}^{2}$ for the 743 cyclic-singlet geometries. This level of precision is required in order to obtain reliable cubic and especially quartic force constants. The QFFs were used in the second-order vibrational perturbation theory program (PT) SPECTRO $^{54}$ to obtain spectroscopic constants and fundamental vibrational frequencies.

The simple internal coordinates, i.e, $\mathrm{HC} 1, \mathrm{C} 1 \mathrm{C} 2, \mathrm{C} 2 \mathrm{~N}$, for the quasilinear triplet and bent singlet structures are given in Figure 1a and 1b, respectively, while the formula for the two quasilinear 
coordinates (A1 and A2) are:

$$
\begin{aligned}
& \alpha_{a b c d}^{x}=\cos \tau_{a b c d} \cdot \sin \phi_{b c d} \\
& \alpha_{a b c d}^{y}=\sin \tau_{a b c d} \cdot \sin \phi_{b c d}
\end{aligned}
$$

where

$$
\sin \tau_{a b c d}=\vec{e}_{b a} \cdot\left(\vec{e}_{c b} \times \vec{e}_{c d}\right) /\left(\sin \phi_{a b c} \cdot \sin \phi_{b c d}\right),-\pi / 2<\tau_{a b c d}<3 \pi / 2
$$

The reference structure for the quasilinear triplet was obtained at the RCCSD(T)/cc-pV5Z level of theory, corrected for core-correlation, where the values are $\mathrm{HC} 1=1.0699 \AA, \mathrm{C} 1 \mathrm{C} 2=1.3274 \AA$, $\mathrm{C} 2 \mathrm{~N}=1.1850 \AA, \mathrm{A} 1(\angle \mathrm{HC} 1 \mathrm{C} 2)=145.07$ and $\mathrm{A} 2(\angle \mathrm{C} 1 \mathrm{C} 2 \mathrm{~N})=175.46^{\circ}$. The reference structure for the bent singlet was obtained using the $\operatorname{CCSD}(\mathrm{T}) / \mathrm{cc}-\mathrm{pV} 5 \mathrm{Z}$ level of theory, again corrected for corecorrelation, which gave $\mathrm{HC} 1=1.0960 \AA, \mathrm{C} 1 \mathrm{C} 2=1.3864 \AA, \mathrm{C} 2 \mathrm{~N}=1.1756 \AA, \mathrm{A} 1(\angle \mathrm{HC} 1 \mathrm{C} 2)=$ $109.65^{\circ}$ and $\mathrm{A} 2(\angle \mathrm{C} 1 \mathrm{C} 2 \mathrm{~N})=172.42^{\circ}$.

For the cyclic isomer we choose the $\mathrm{HC} 1, \mathrm{C} 1 \mathrm{~N} 2, \mathrm{C} 1 \mathrm{C} 3$ bond distances and bond angles $\mathrm{A} 1(\angle \mathrm{HC} 1 \mathrm{~N} 2), \mathrm{A} 2(\angle \mathrm{N} 2 \mathrm{C} 1 \mathrm{C} 3)$, shown in figure 1c. The angle $\gamma$ refers to the out-of-plane bending angle for the $\mathrm{H}-\mathrm{C}$ bond with respect to the plane defined by the three $\mathrm{C}$ and $\mathrm{N}$ atoms, the formula is here:

$$
\gamma_{a b c d}=\sin ^{-1}\left[\vec{e}_{b a} \cdot\left(\vec{e}_{b c} \times \vec{e}_{b d}\right) / \sin \phi_{b c d}\right]
$$

where $\vec{e}$ is a unit vector defined as $\vec{e}_{a b}=\vec{e}_{b}-\vec{e}_{a}$ with $\mathbf{b}$ at the center and $\mathbf{a}$ as $\mathrm{H}$ atom.

The reference structures was determined at the $\operatorname{CCSD}(\mathrm{T}) / \mathrm{cc}-\mathrm{pV} 5 \mathrm{Z}$ level of theory (corrected for core-correlation), where the values are $\mathrm{HC} 1=1.0762 \AA, \mathrm{C} 1 \mathrm{~N} 2=1.2937 \AA, \mathrm{C} 1 \mathrm{C} 3=1.3976 \AA$ and $\mathrm{A} 1(\angle \mathrm{HC} 1 \mathrm{~N} 2)=138.05^{\circ}, \mathrm{A} 2(\angle \mathrm{N} 2 \mathrm{C} 1 \mathrm{C} 3)=62.11^{\circ}$.

Spectroscopic constants have been determined using standard second-order asymmetric top perturbation theory (PT) using the SPECTRO program ${ }^{54}$. Vibrational fundamental frequencies are also determined variationally (VCI), using the MULTIMODE program ${ }^{55,56}$. For the cyclic and bent singlet structures, tests were performed to ensure that the VCI calculations are converged to better than $1 \mathrm{~cm}^{-1}$ with respect to mode coupling (five mode coupling was used) and the size of the VCI basis set. As discussed more below, for the triplet state, the quasilinear nature causes a problem with the VCI calculations. For the variational calculations, QFFs are transformed to a Morse-cosine

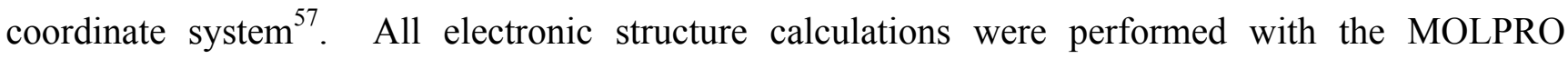


program suite ${ }^{45}$

\section{RESULTS AND DISCUSSIONS}

\section{A. Equilibrium Structures, Harmonic Frequencies and Equilibrium Rotational Constants}

The Tables 1-3 summarize the equilibrium geometries, equilibrium rotational constants, and harmonic vibrational frequencies for the quasilinear triplet, bent singlet and cyclic singlet, respectively. We have included various methods in order to compare different approximations. "2-pt" or "3-pt" are used to represent to the one particle basis set limit based on either the two-point (1) or three-point (2) formula described in the previous section, "core" for core correlation, "rel" for the scalar relativistic correction, "PT" for the second-order perturbation theory using the SPECTRO program, and "VCI" for vibrational configuration interaction using the MULTIMODE program. The results computed with the two-point, 2-pt(tz,qz), extrapolation formula are reported first, then we compare with the 2-pt(qz,5z) results and the three-point extrapolation formula, 3-pt(tz,qz,5z), results, followed by the $5 \mathrm{z}$ basis set (which means the cc-pv5Z basis) plus core-correlation and relativistic corrections.

The molecular structure of the quasilinear triplet and bent singlet are shown in Figures 1a and 1b, respectively. Here, bond distance coordinates are $\mathrm{HC} 1, \mathrm{C} 1 \mathrm{C} 2$, and $\mathrm{C} 2 \mathrm{~N}$, with two in-plane bending angles, $\angle \mathrm{HC} 1 \mathrm{C} 2$ and $\angle \mathrm{C} 1 \mathrm{C} 2 \mathrm{~N}$, denoted respectively by $\mathrm{A} 1$ and $\mathrm{A} 2$. The coordinates for the cyclic singlet structure were defined in the previous section and are shown in Figure 1c.

Compared to the reference structure used to set up the generation of the QFFs, examination of our various results, we note that the best match is found at the 3-pt(tz,qz,5z)+core+rel level of theory, where the differences are less than 0.001 angstrom, between bond distance $\mathrm{HC} 1, \mathrm{C} 1 \mathrm{C} 2$, and $\mathrm{C} 2 \mathrm{~N}$, and 0.1 to 0.01 degrees, for angles A1 and A2. The same result is observed for all three isomers studied here as found by examining the results in Tables 1-3. As the reference geometry is confirmed to be very close to the minimum on our best QFF (3-pt(tz,qz,5z)+core+rel), we are able to assert that the highest level of theory QFF reported here, denoted as 3-pt(tz,qz,5z)+core+rel, should yield near quantitative accuracy.

For all three isomers, comparison of the 2-pt(tz,qz), 2-pt(qz,5z), and 3-pt(tz,qz,5z) results shows small differences between the first two methods and very small differences between the latter two approaches, consistent with our earlier studies ${ }^{47,58}$. That is, the difference between the 2-pt and 3-pt extrapolations is relatively small provided both include the $5 z$ basis set, but the 2-pt(tz,qz) results are noticeably less converged. We note, however, that the 3-pt(tz,qz,5z) results are consistent with being 
slightly more converged with respect to one-particle basis set completeness, and thus the 3-pt(tz,qz,5z) approach is preferred.

Comparison of the 3-pt(tz,qz,5z) and 3-pt(tz,qz,5z)+core results for all three isomers shows that core-correlation has the expected result of shortening bond lengths and increasing the stretching harmonic frequencies somewhat. Comparison of the 3-pt(tz,qz,5z)+core and 3-pt(tz,qz,5z)+core+rel results shows that scalar relativistic effects are relatively small for all three isomers, with the largest effect on a bond distance being only $0.0002 \AA$, and the largest effect on a harmonic frequency being less than $3 \mathrm{~cm}^{-1}$. It is interesting that comparison of the $5 \mathrm{z}+$ core + rel and $3-p t(t z, q z, 5 z)+$ core + rel results for all three isomers shows relatively small differences, the effect on any harmonic frequency being less than $3 \mathrm{~cm}^{-1}$, for example. This shows that for these molecular isomers, at least, convergence with respect to the one-particle basis set limit is rapid, which is not always the case. Our most complete results are those obtained at the 3-pt(tz,qz,5z)+core+rel level of theory, and the remainder of the discussion will focus on these.

In Table 1, our best results at the 3-pt(tz,qz,5z)+core+rel level are in good agreement with the available experimental data for the $\mathrm{C} 1 \mathrm{C} 2$, and $\mathrm{C} 2 \mathrm{~N}$ bond lengths. With respect to the experimental $\mathrm{HC} 1$ bond distance, Brown et al. ${ }^{22}$ found that this bond is shorter than all known $\mathrm{C}-\mathrm{H}$ bond lengths previously determined in other hydrocarbon molecules, suggesting that an accurate study was necessary to understand the HCCN structure. However, they obtained this short $\mathrm{CH}$ bond distance by assuming a linear structure, but later studies have shown that the triplet ground state of HCCN is best viewed as quasilinear ${ }^{23-29}$, and our results support that conclusion.

Comparison of our best equilibrium structure and harmonic frequency of the quasilinear triplet isomer with previous theoretical results shown in Table 1, not surprisingly we find better agreement with the study by Koput et al. ${ }^{36}$ who used the CCSD(T)/cc-pVQz level of theory. The other previous theoretical results were obtained with the $\operatorname{CCSD}(\mathrm{T})$ [or QCISD(T)] method, but using only a polarized double zeta (DZP) quality basis set, leading to bond distances that are too long and harmonic stretching frequencies that are too low. While the differences between our best results and those of Koput et al. ${ }^{36}$ are relatively small, the $3-p t(t z, q z, 5 z)+c o r e+r e l$ values for the equilibrium structure and harmonic frequencies should be the most reliable determined to date.

For the bent singlet and cyclic singlet isomers in Tables 2 and 3, respectively, there are no experimental data available, and the only previous theoretical results were obtained at the QCISD(T)/D95** level of theory ${ }^{59}$ (Kassaee et al. ${ }^{39}$ did not report equilibrium structures nor harmonic frequencies). Thus their bond distances are much too long and the stretching harmonic frequencies are 
too high relative to our best results. The equilibrium structures and harmonic frequencies obtained here with the 3-pt(tz,qz,5z)+core+rel level of theory should be the most reliable available for the bent and cyclic singlet isomers of $\mathrm{HCCN}$.

In the following section, we present and discuss our findings for the anharmonic fundamental vibrational frequencies and other spectroscopic constants of the quasilinear triplet, bent singlet, and cyclic singlet isomers of $\mathrm{HCCN}$.

\section{B. Fundamentals frequencies, Effective rotational constants and quartic and sextic centrifugal distortion constants.}

Effective rotational constants, centrifugal distortion constants and fundamental vibrational frequencies are given in Tables 4 through 6 for the quasilinear triplet, bent singlet, and cyclic singlet isomers, respectively. These data allow us to compare different approximations applied in this work. For the quasilinear triplet isomer, see Table 4 , the $C_{0}$ effective rotational constant from our best purely ab initio QFF is only $7 \mathrm{MHz}$ lower than the experimental value obtained by McCarthy et al. ${ }^{23}$ and Saito et al. ${ }^{17}$, while the theoretical result of Mladenovic et al. ${ }^{59}$ underestimates the experimental value by more than $47 \mathrm{MHz}$. Further, agreement between experiment and our best QFF for the $B_{0}$ vibrationally averaged rotational constant is also very good, being only $16 \mathrm{MHz}$ too high. This agreement between the predicted and observed values of the effective $B_{0}$ and $C_{0}$ rotational constants is a strong confirmation of the accuracy of the calculated spectroscopic constants of cyanocarbene in this work. On the other hand, we note that for the quasilinear triplet isomer, there is an extremely large difference between the $A_{\mathrm{e}}$ and $A_{0}$ values, suggesting a very large vibrational contribution. This result can be attributed to the large corrections from the quartic and sextic centrifugal distortion constants, but this probably means that $2^{\text {nd }}$-order vibrational perturbation theory is not adequate. This result is consistent with the experimental studies showing that the triplet ground state is a quasilinear molecule. Interestingly, the bent singlet does not exhibit this behavior. That is, there is not an overly large vibrational contribution to the $A_{0}$ vibrationally averaged rotational constant as shown in Table 5 . Quartic and sextic centrifugal distortion constants are also included in Tables 4-6. We note that for the triplet isomer, the computed value for $D_{J}$ from our best QFF, 3-pt(tz,qz,5z)+core+rel, agrees very well with the experimental value of $0.0041 \mathrm{MHz}$ given by Saito et al. ${ }^{17}$. The theoretical results presented here for the vibrationally averaged rotational constants of the bent and cyclic singlet isomers should facilitate future high-resolution astronomical or experimental analyses.

Table 4 shows the vibrational fundamental frequencies for the quasilinear triplet isomer using 
the PT and VCI methods applied in this work. Several resonances have been detected in the PT analyses (indicated in the table) and these have been handled in the usual polyad formulation. ${ }^{60}$ For the PT results, the agreement amongst the various approaches mostly mirrors that found for the harmonic frequencies. That is, the $2 \mathrm{pt}(\mathrm{qz}, 5 \mathrm{z})$ results are similar to the $3 \mathrm{pt}(\mathrm{tz}, \mathrm{qz}, 5 \mathrm{z})$ values, while the $5 z+$ core + rel quantities are similar to the $3 p t(t z, q z, 5 z)+$ core + rel values. The one small exception, is that the variation for $v_{4}$ amongst the various methods is larger, as large as $8.4 \mathrm{~cm}^{-1}$ between $5 \mathrm{z}+$ core + rel and $3 \mathrm{pt}(\mathrm{tz}, \mathrm{qz}, 5 \mathrm{z})+\mathrm{core}+\mathrm{rel}$. The differences between PT and VCI, however, are significantly larger than we normally see, even for the $\mathrm{CH}$ stretching mode, $v_{1}$. In fact, the discrepancy between PT and VCI is very large for $v_{4}$ through $v_{6}$, suggesting that a QFF is not really adequate to describe properly the anharmonic nature of the ground state triplet isomer. These results are, of course, consistent with the quasilinearity of the triplet state that has been noted previously. Agreement between our best fundamental vibrational frequencies, those arising from the $3 \mathrm{pt}(\mathrm{tz}, \mathrm{qz}, 5 \mathrm{z})+\mathrm{core}+\mathrm{rel}$ QFF, and the best previous theory from Mladenovic et al. ${ }^{59}$ is mixed. The PT value for $v_{1}$ agrees reasonably well (difference of only $3.7 \mathrm{~cm}^{-1}$ ), but for $v_{2}$ and $v_{3}$ the agreement is less good, with differences of 10.9 and $19.3 \mathrm{~cm}^{-1}$, respectively. On the other hand, if we compare our VCI results we find that the agreement for $v_{3}$ is reasonable, but the agreement for $v_{1}$ and $v_{2}$ is poor, especially for $v_{2}$ where we find a strong coupling with another state. Comparison of our best PT fundamental vibrational frequencies with experiment for the stretching modes $\left(v_{1}, v_{2}\right.$, and $\left.v_{3}\right)$ shows reasonable agreement with differences on the order of $10-20 \mathrm{~cm}^{-1}$, though nowhere near as good as we have come to expect with this level of theory. The experimental results themselves for $v_{4}$ through $v_{6}$ are significantly varied, and so it is not a surprise that our results are in poor agreement. Again, all of this supports the previous conclusion that the ground state triplet isomer is a quasilinear molecule with significant coupling of its vibrational degrees of freedom, and our results show definitively that a QFF does not describe enough of the potential energy surface near the minimum to describe properly the vibrational fundamental frequencies. This is true even for VCI calculations where the QFF is transformed into a Morse-cosine coordinate system with better limiting behavior, or rather for the bending coordinate the cosine function ensures that the potential is multi-welled. This is in contrast to our earlier study on HNO, which possesses a very anharmonic H-N stretching motion. ${ }^{60}$ There, the VCI calculations with a QFF transformed into the Morse-cosine coordinate system performed very well even though the PT results were relatively poor.

Tables 5 and 6 contain the vibrationally averaged rotational constants, the quartic and sextic centrifugal distortion constants, and the fundamental vibrational frequencies for the bent singlet and 
the cyclic singlet isomers, respectively. Comparison of the PT results for the various levels of theory included shows similar behavior to that found for the equilibrium structures and harmonic frequencies. That is, differences between $2 \mathrm{pt}(\mathrm{qz}, 5 \mathrm{z})$ and $3 \mathrm{pt}(\mathrm{tz}, \mathrm{qz}, 5 \mathrm{z})$ are small, while differences between $2 p t(t z, q z)$ and $3 p t(t z, q z, 5 z)$ are larger; for most vibrational fundamentals, differences between $5 \mathrm{z}+$ core + rel and $3 \mathrm{pt}(\mathrm{tz}, \mathrm{qz}, 5 \mathrm{z})+\mathrm{core}+$ rel are relatively small, suggesting that one-particle basis set convergence is relatively rapid for these isomers; and scalar relativistic effects are relatively small (the largest effect on a given fundamental frequency is 1.5 and $1.4 \mathrm{~cm}^{-1}$ for the bent and cyclic isomers, respectively). Moreover, the agreement between the PT and VCI methodologies for the $3 p t(t z, q z, 5 z)+$ core + rel QFF is very good for all six fundamental vibrational frequencies for both the bent and cyclic singlet isomers, with the largest differences being $9.5 \mathrm{~cm}^{-1}$ and $4.0 \mathrm{~cm}^{-1}$ for $v_{5}$ and $v_{2}$ of the cyclic singlet, respectively. The largest difference for the bent singlet is only $1.4 \mathrm{~cm}^{-1}$ for $v_{4}$. There are no high-resolution experimental data with which to compare for the bent and cyclic singlet, but the agreement between PT and VCI together with the evidence that one-particle basis set convergence is nearly complete, suggests that the fundamental vibrational frequencies and other spectroscopic constants obtained from the $3 \mathrm{pt}(\mathrm{tz}, \mathrm{qz}, 5 \mathrm{z})+$ core+rel QFF should be very reliable. It is hoped that these will be useful in the interpretation of future high-resolution spectra obtained either from an astronomical observation or a laboratory experiment.

\section{Force constants, anharmonic constants, and vibration-rotation interaction constants.}

For completeness, the asymmetric top anharmonic constants for the quasilinear triplet, bent singlet, and cyclic singlet are presented in Tables 7-9, respectively, the quadratic, cubic and quartic force fields are given in Tables 10-12, respectively, and the $\alpha$ vibration-rotation interaction constants are given in Table 13. The respective 3pt(tz,qz,5z)+core+rel QFFs were used to generate the data in Tables 7-13. Also, constants which are affected by any included Fermi and/or Coriolis resonances are indicated in the Tables. As indicated, the QFFs and spectroscopic constants for the bent and cyclic singlet isomers should be very accurate and reliable. For the triplet isomer, constants involving the stretching modes will be more reliable than those involving bending or torsional motions, but higherorder force constants (i.e., beyond a QFF) are needed in order to describe more accurately the rovibrational properties of this isomer. Nonetheless, the $3 \mathrm{pt}(\mathrm{tz}, \mathrm{qz}, 5 \mathrm{z})+\mathrm{core}+\mathrm{rel} \mathrm{QFF}$ we present for the triplet isomer should be the most accurate available and it should be a good place to start for construction of a larger potential function. 


\section{Isomeric energy differences and dipole moments.}

Finally, the relative energies of the three $\mathrm{HC}_{2} \mathrm{~N}$ isomers included in the present study are collected in Table 14 together with their dipole moment values. The relative energies are presented with and without correction for zero-point energies. The zero-point energies are taken from the VCI calculations, but there was essentially no difference if PT zero-point energies were used instead. The first point to note is that consistent with earlier studies, we find the triplet isomer to be the lowest in energy, followed by the cyclic singlet $7.8 \mathrm{kcal} / \mathrm{mol}$ higher in energy (zero-point energies included), and then the bent singlet $11.1 \mathrm{kcal} / \mathrm{mol}$ higher in energy relative to the ground state triplet. The energy differences reported in Table 14 should be the most reliable available for these three isomers. Further, as there is likely a large barrier preventing interconversion, all three isomers should be long lived in an astrophysical environment with low collision rates and with negligible levels of ionizing radiation.

It is hoped that the data contained herein for the ground state triplet, and the cyclic and bent singlet isomers will aid in the interpretation of future laboratory experiments or astronomical observations. The large dipole moment values of $3.05 \mathrm{D}, 3.06 \mathrm{D}$, and $1.71 \mathrm{D}$ (computed at the $\operatorname{CCSD}(\mathrm{T}) / \mathrm{cc}-\mathrm{pVQZ}$ level of theory) for the triplet, cyclic singlet, and bent singlet, respectively, mean that all three isomers should be easily observable in rotational spectroscopy provided there is a larger enough population.

\section{CONCLUSIONS}

In the present contribution, we have characterized the quasilinear triplet, bent singlet, and cyclic singlet $\mathrm{HC}_{2} \mathrm{~N}$ isomers and determined their molecular properties. We have calculated a series of highly accurate $a b$ initio QFFs based on the $\operatorname{CCSD}(\mathrm{T})$ level of theory together with extrapolation to the one-particle basis set limit and inclusion of core-correlation and scalar relativistic corrections. These are the most accurate purely ab initio QFFs available for these $\mathrm{HC}_{2} \mathrm{~N}$ isomers.

Consistent with earlier studies, we find that the most stable conformer of $\mathrm{HC}_{2} \mathrm{~N}$ is the quasilinear triplet cyanomethylene (figure 1a), followed by the cyclic singlet isomer $(7.8 \mathrm{kcal} / \mathrm{mol}$ higher in energy), and then the bent singlet isomer $11.1 \mathrm{kcal} / \mathrm{mol}$ above the ground state triplet.

It was known that the ground state bent triplet species is quasilinear, and we find that a QFF is not adequate for describing all of the fundamental vibrational frequencies and spectroscopic constants. Specifically, the purely stretching fundamental frequencies and analogous spectroscopic constants are

reasonably well described by $2^{\text {nd }}$-order perturbation theory (there is still a small effect due to coupling with the quasilinear modes), but the bending and torsion modes and related spectroscopic constants 
are poorly described, especially those constants related to the $A_{0}$ rotational constant. Agreement with experiment for frequencies and spectroscopic constants involving the stretching modes is reasonable, while for the bending and torsion modes the agreement is significantly degraded due to the quasilinear nature of the triplet state. On the other hand, VCI calculations using the QFF transformed into a Morse-cosine coordinate system (which has better limiting behavior) are relatively poor, even for the stretching fundamentals, indicating that a QFF is not adequate.

Interestingly, however, both the cyclic and bent singlet isomers are well described using a QFF. That is, the fundamental vibrational frequencies are well behaved as evidenced by the very good agreement between PT and VCI for solving the nuclear Schrödinger equation. The spectroscopic constants also exhibit reasonable behavior, with the $A_{0}$ constant having a reasonable value, but also consistent from one level of theory to another.

Fundamental vibrational frequencies and rovibrational spectroscopic constants from our best QFF, labeled 3pt(tz,qz,5z,)+core+rel, should be the most reliable available for the cyclic and bent singlet isomers, and it is hoped that these will be useful in the interpretation of a spectrum from a high-resolution astronomical observation or a laboratory experiment. Moreover, some of the data we report here for the quasilinear triplet species, such as the equilibrium structure and the harmonic frequencies, should also be the most accurate available - but the anharmonic analysis is lacking due to inadequacies in the use of a QFF for this quasilinear isomer.

Dipole moments were calculated using the best equilibrium geometry for each isomer at the $\operatorname{CCSD}(\mathrm{T}) / \mathrm{cc}-\mathrm{pVQZ}$ level of theory $(\operatorname{RCCSD}(\mathrm{T}) / \mathrm{cc}-\mathrm{pVQZ}$ for the ground state triplet). All three isomers possess a large dipole moment $(3.05 \mathrm{D}, 3.06 \mathrm{D}$, and $1.71 \mathrm{D}$, for the triplet, cyclic singlet, and bent singlet isomers, respectively). Thus, all three should be easily observed and identified using modern telescopes such as Herschel, SOFIA, or ALMA, provided there is sufficient numbers of these isomers present.

The quasilinear triplet isomer of $\mathrm{HC}_{2} \mathrm{~N}$ has already been identified in astronomical observations, but the cyclic and bent singlet geometrical isomers are also good candidates for astrophysical observation by microwave and infrared spectroscopy. This is due to the fact that both the cyclic and singlet isomers possess rather large dipole moments, but more importantly the cyclic isomer is isoelectronic to cyclopropenylidene, which has been identified in many different astrophysical environments. Moreover, the major formation pathway for cyclopropenylidene is thought to occur through dissociative attachment of an electron to the protonated form, and the analogous pathway for $\mathrm{HC}_{2} \mathrm{~N}$ again favors the cyclic isomer since the most stable form of $\mathrm{C}_{2} \mathrm{H}_{2} \mathrm{~N}^{+}$is a cyclic isomer. 
Due to the high probability of the existence of these isomers in astrophysical environments, especially the cyclic form, we have determined highly accurate QFFS and from these their fundamental vibrational frequencies and spectroscopic constants to aid in the interpretation of future astronomical observations from ALMA, Herschel, or SOFIA, or high-resolution laboratory experiments.

\section{Acknowledgements}

TJL and XH gratefully acknowledge support from NASA grant 08-APRA08-0050 and NASA grant 10-APRA10-0096. XH also acknowledges support from the NASA/SETI Institute Cooperative Agreement NNX09AI49A. N.I. wants to acknowledge the Fondecyt grants 3110007 and P. Fuentealba for helpful advice. Support from Timothy J. Lee and NASA Ames Research Center is also gratefully acknowledged. 


\section{REFERENCES}

[1]B. E. Turner, Astrophys. J. Lett. 163, L35 (1971).

[2]L. E. Snyder and D. Buhl, Astrophys. J. Lett. 163, L47 (1971).

[3]G. Winnewisser and C. M. Walmsley, Astron. Astrophys. 70, L37 (1978).

[4]N. W. Broten, T. Oka, L. W. Avery, J. M. MacLeod, and H. W. Kroto, Astrophys. J. Lett. 223, L105 (1978).

[5]M. Oishi, D. McGonagle, W. M. Irvine, and S. Yamamoto, Astrophys. J. Lett. 427, L51 (1994).

[6]B. Bell, P. A. Feldman, M. J. Travers, M. C. McCarthy, C. A. Gottlieb, and P. Thaddeus, Astrophys. J. Lett. 483, L61(1997).

[7]J. Cernicharo, M. Guélin, and J. R. Pardo, Astrophys. J. Lett. 615, L145 (2004).

[8]M. Guélin and J. Cernicharo, Astron. Astrophys. 244, L21 (1991).

[9]T. J. Lee, A. Bunge and H. F. Schaefer, J. Am. Chem. Soc. 107, 137 (1985).

[10]T. J. Lee, X. Huang, and C. E. Dateo, Mol. Phys. 107, 1139 (2009).

[11]P. Thaddeus, J. M.Vrtilek, C.A. Gottlieb, Astrophys. J. 299, L63 (1985).

[12]M. B.Bell, P. A.Feldman, H. E.Matthews, L. W. Avery, Astrophys. J. 311, 1989 (1986).

[13]T. Oike, K. Kawaguchi, S. Takano, N. Nakai, Publ. Astron. Soc. Jap. 56, 4310 (2004).

[14]X. Huang, P. R. Taylor, and T. J. Lee, J. Phys. Chem. A 115, 5005 (2011).

[15]N.Goldberg, A. Fiedler, and H. Schwarz, J. Phys. Chem. 99, 15327, (1995).

[16]A. Dendramis and G. E. Leroi, J. Chem. Phys. 66, 4334 (1977).

[17]S. Saito, Y. Endo, and E. Hirota, J. Chem. Phys. 80, 1427, (1984).

[18]R. A. Bernheim, R. J. Kempf, P. W. Humer, and P. S. Skell, J. Chem. Phys. 41, 1156 (1964).

[19]R. A. Bernheim, R. J. Kempf, J. V. Gramas, and P. S. Skell, J. Chem. Phys. 43, 196 (1965).

[20] R. A. Bernheim, R. J. Kempf, and E. F. Reichenbecher, J. Magn. Reson. 3, 5 (1970).

[21]E. Wasserman, W. A. Yager, and V. J. Kuck, Chem. Phys. Lett. 7, 409 (1970).

[22]F. X. Brown, S. Saito, and S. Yamamoto, J. Mol. Spectrosc. 143, 203 (1990).

[23]M. C. McCarthy, C. A. Gottlieb, A. L. Cooksy, P. Thaddeus, J. Chem. Phys. 103, 7779 (1995).

[24]C. L. Morter, S. K. Farhat, R. F. Curl, Chem. Phys. Lett. 207, 153 (1993).

[25]C. E. Miller, W. C. Eckhoff, R. F. Curl, J. Mol. Struct. 435, 352, (1995).

[26]F. Sun, A. Kosterev, G. Scott, V. Litosh, R. F. Curl, J. Chem. Phys. 109, 8851 (1998).

[27]J. Han, P. Y. Hung, J. DeSain, W. E. Jones, R. F. Curl, J. Mol. Spectrosc. 198, 421 (1999).

[28]P. Y. Hung, F. Sun, N. T. Hunt, L. A. Burns, R. F. Curl, J. Chem. Phys. 115, 9331 (2001).

[29]M. D. Allen, K. M. Evenson, J. M. Brown, J. Mol. Spectrosc. 209, 143 (2001).

[30]M. R. Nimlos, G. Davico, C. M. Geise, P. G. Wenthold, W. C. Lineberger, S. J. Blanksby, C.

M. Hadad, G. A. Petersson, and G. B. Ellison, J. Chem. Phys. 117, 4323 (2002).

[31]J. E. Rice and H. F. Schaefer, J. Chem. Phys. 86, 7051 (1987). 
[32]E. T. Seidl and H. F. Schaefer, J. Chem. Phys. 96, 4449 (1992).

[33]K. Raghavachari, G. W. Trucks, J. A. Pople, and M. Head-Gordon, Chem. Phys. Lett. 157, 479 (1989).

[34]B. O. Roos, P. R. Taylor, P. E. M. Siegbahn, Chem. Phys. 48, 157 (1980) .

[35]P._A. Malmqvist, R. Lindh, B. O. Roos, and S. Ross, Theor. Chem. Acc. 73, 155 (1988).

[36]J. Koput, J. Phys. Chem. A 106, 6183 (2002).

[37]K. Aoki, S. Ikuta, J. Chem. Phys. 99, 3809 (1993).

[38]S.-W. Park and S. Lee, Bull. Korean Chem. Soc. 23, 1553 (2002).

[39]M. Z. Kassaee, M. Ghambarian, and S. M. Musavi, Heteroatom Chem. 19, 377 (2008).

[40]G. E. Scuseria, A. C. Scheiner, T. J. Lee, J. E. Rice and H. F. Schaefer, J. Chem. Phys. 86, 2881 (1987).

[41] T. J. Lee and J. E. Rice, Chem. Phys. Lett. 150, 406 (1988).

[42]A. P. Rendell, T. J. Lee and A. Komornicki, Chem. Phys. Lett. 178, 462 (1991).

[43]P. J. Knowles, C. Hampel, H. J. Werner, J. Chem. Phys. 99, 5219 (1994).

[44]P. J. Knowles, C. Hampel, H. J. Werner, J. Chem. Phys. 112, 3106 (2000)

[45]H. J. Werner, MOLPRO, version 2008.1, a package of ab initio programs; 2008; see http://www.molpro.net.

[46]T. H., Dunning Jr., J. Chem. Phys. 90, 1007 (1989).

[47]X. Huang and T. J. Lee, J. Chem. Phys. 129, 044312 (2008).

[48]M. Douglas and N. M. Kroll, Ann. Phys. 82, 89 (1974).

[49]B. A. Hess, Phys. Rev. A 32, 756 (1985).

[50]B. A. Hess, ibid. 33, 3742 (1986).

[51]J. M. L. Martin and P. R. Taylor, Chem. Phys. Lett. 225, 473 (1994).

[52]T. Helgaker, W. Klopper, H. Koch, and J. Noga, J. Chem. Phys. 106, 9639 (1997).

[53]J. M. L. Martin and T. J. Lee, Chem. Phys. Lett. 258, 136 (1996).

[54]SPECTRO, version 3.0, written by J. F. Gaw, A. Willets, W. H. Green, and N. C. Handy (1996).

[55]S. Carter, J. M. Bowman, and N. C. Handy, Theor. Chem. Acc. 100, 191(1998);

[56]J. M. Bowman, S. Carter, and X. Huang, Int. J. Rev. Phys. Chem. 22, 533 (2003).

[57]C. E. Dateo, T. J. Lee, and D. W. Schwenke, J. Chem. Phys. 101, 5853 (1994).

[58]X. Huang and T. J. Lee, J. Chem. Phys. 131, 104301 (2009).

[59]M. Mladenovic, P. Botschwina and C. Puzzarini, J. Phys. Chem. A 110, 5520 (2006).

[60]J. M. L. Martin, T. J. Lee, P. R. Taylor, and J.-P. Francois, J. Chem. Phys. 103, 2589 (1995). 
Figure 1: Structure of $3 \mathrm{HC}_{2} \mathrm{~N}$ Isomers. (a) $\mathrm{X}^{3} A^{\prime \prime}$ Ground state triplet; (b) $\mathrm{X}^{1} A^{\prime}$ Bent singlet; (c) $\mathrm{X}^{1} A^{\prime}$ Cyclic singlet

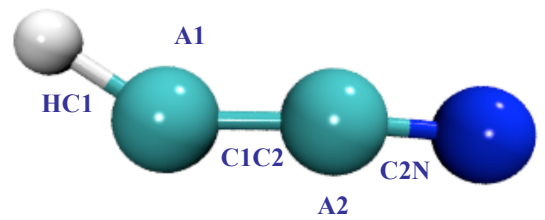

(a)

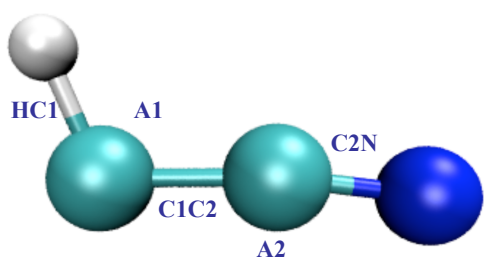

(b)

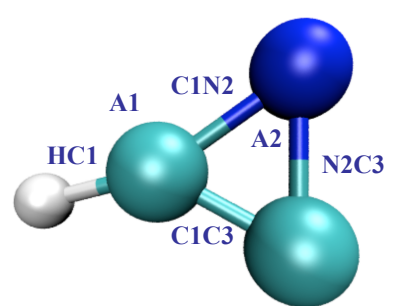

(c) 
Table 1. Equilibrium geometries ( $\AA$, degree), equilibrium rotational constants ( $\mathrm{MHz})$ and harmonic frequencies $\left(\mathrm{cm}^{-1}\right)$ of bent-triplet $\mathrm{HC}_{2} \mathrm{~N}$ at $\mathrm{RCCSD}(\mathrm{T})$ level of theory (see text for more details).

\begin{tabular}{|c|c|c|c|c|c|c|c|c|c|}
\hline \multirow{2}{*}{$\begin{array}{c}\text { Ground } \\
\text { State } \\
\text { triplet }\end{array}$} & \multicolumn{6}{|c|}{ This work } & \multicolumn{3}{|c|}{ Previous work } \\
\hline & $\begin{array}{c}\text { 2-pt } \\
(\mathbf{t z}, \mathbf{q z})\end{array}$ & $\begin{array}{c}2-p t \\
(q z, 5 z)\end{array}$ & $\begin{array}{c}\text { 3-pt } \\
(\mathbf{t z}, \mathbf{q z}, \mathbf{5 z})\end{array}$ & $\begin{array}{c}5 z \\
+ \text { core }+ \text { rel }\end{array}$ & $\begin{array}{c}\text { 3-pt } \\
(\mathbf{t z , q z , 5 z )} \\
\quad+\text { core }\end{array}$ & $\begin{array}{c}\text { 3-pt } \\
(\mathrm{tz}, \mathrm{qz}, 5 \mathrm{z}) \\
+ \text { core+rel }\end{array}$ & $\operatorname{Exp}$ & The & ory \\
\hline HC1 & 1.0702 & 1.0704 & 1.0705 & 1.0691 & 1.0689 & 1.0689 & $0.998^{\text {(a) }}$ & $1.069^{(\mathrm{b})}$ & $1.082^{(\mathrm{c})}$ \\
\hline $\mathrm{C} 1 \mathrm{C} 2$ & 1.3288 & 1.3299 & 1.3303 & 1.3273 & 1.3269 & 1.3267 & $1.323^{\text {(a) }}$ & $1.328^{(b)}$ & $1.357^{(\mathrm{c})}$ \\
\hline $\mathrm{C} 2 \mathrm{~N}$ & 1.1862 & 1.1872 & 1.1876 & 1.1853 & 1.1852 & 1.1850 & $1.195^{\text {(a) }}$ & $1.186^{(\mathrm{b})}$ & $1.208^{(\mathrm{c})}$ \\
\hline $\mathrm{A} 1(\mathrm{HC} 1 \mathrm{C} 2)$ & 144.89 & 144.61 & 144.53 & 144.99 & 145.03 & 144.95 & ----- & $144.9^{(b)}$ & $147.0^{(\mathrm{c})}$ \\
\hline $\mathrm{A} 2(\mathrm{C} 1 \mathrm{C} 2 \mathrm{~N})$ & 175.41 & 175.37 & 175.36 & 175.44 & 175.48 & 175.45 & ---- & $175.4^{(b)}$ & $174.6^{(\mathrm{c})}$ \\
\hline$A_{e}$ & 1681210 & 1656675 & 1649291 & 1693550 & 1697149 & 1690595 & & & $337775^{(\mathrm{d})}$ \\
\hline $\boldsymbol{B}_{e}$ & 11037 & 11022 & 11016 & 11058 & 11061 & 11065 & & & $10687^{(\mathrm{d})}$ \\
\hline$C_{e}$ & 10965 & 10949 & 10943 & 10986 & 10989 & 10993 & & & $10603^{(\mathrm{d})}$ \\
\hline$\omega_{1}\left(\mathbf{A}^{\prime}\right)$ & 3343.8 & 3341.6 & 3341.0 & 3350.0 & 3349.8 & 3349.0 & & 3340 & (b) $3333^{\text {(d) }}$ \\
\hline$\omega_{2}\left(\mathbf{A}^{\prime}\right)$ & 1865.8 & 1864.5 & 1864.0 & 1869.0 & 1870.1 & 1869.2 & & 1863 & (b) $1818^{\text {(d) }}$ \\
\hline$\omega_{3}\left(\mathbf{A}^{\prime}\right)$ & 1144.3 & 1141.7 & 1140.8 & 1145.6 & 1146.2 & 1145.8 & & 1139 & (b) $1123^{\text {(d) }}$ \\
\hline$\omega_{4}\left(A^{\prime}\right)$ & 574.5 & 578.7 & 580.4 & 574.7 & 571.3 & 572.8 & & & $1^{(\mathrm{b})} 689^{\text {(d) }}$ \\
\hline$\omega_{5}\left(\mathbf{A}^{\prime}\right)$ & 384.5 & 383.5 & 383.4 & 385.4 & 384.4 & 384.2 & & & $0^{(\mathrm{b})} 376^{\text {(d) }}$ \\
\hline$\omega_{6}\left(\mathrm{~A}^{\prime \prime}\right)$ & 427.0 & 426.7 & 426.6 & 428.8 & 429.4 & 428.8 & & & $5^{(\mathrm{b})} 408^{(\mathrm{d})}$ \\
\hline
\end{tabular}

a) From microwave spectra ref. [22] considered as linear structure;

b) From ref. [36] at $\operatorname{CCSD}(\mathrm{T}) / \mathrm{cc}-\mathrm{pVQZ}$ level of theory;

c) From ref. [32] at CCSD(T)/DZP; d) From ref. [37] at QCISD(T)/D95** level of theory. 
Table 2. Equilibrium geometries ( $\AA$, degree), equilibrium rotational constants $(\mathrm{MHz})$ and harmonic frequencies $\left(\mathrm{cm}^{-1}\right)$ of bent-Singlet $\mathrm{HC}_{2} \mathrm{~N}$ at $\mathrm{CCSD}(\mathrm{T})$ level of theory (see text for more details).

\begin{tabular}{|c|c|c|c|c|c|c|c|}
\hline \multirow{2}{*}{$\begin{array}{c}\text { Bent } \\
\text { Singlet }\end{array}$} & \multicolumn{6}{|c|}{ This work } & \multirow{2}{*}{$\begin{array}{c}\begin{array}{c}\text { Previous } \\
\text { work }\end{array} \\
\text { Theory }\end{array}$} \\
\hline & $\begin{array}{c}2-p t \\
(t z, q z)\end{array}$ & $\begin{array}{c}2-p t \\
(q z, 5 z)\end{array}$ & $\begin{array}{c}\text { 3-pt } \\
(\mathbf{t z}, q z, 5 z)\end{array}$ & $\begin{array}{c}5 z \\
+ \text { core+rel }\end{array}$ & $\begin{array}{c}\text { 3-pt } \\
(\mathbf{t z , q z , 5 z )} \\
+ \text { core }\end{array}$ & $\begin{array}{c}\text { 3-pt } \\
(\text { tz,qz,5z)+ } \\
\text { core+rel }\end{array}$ & \\
\hline HC1 & 1.0974 & 1.0976 & 1.0977 & 1.0961 & 1.0957 & 1.0958 & $1.106^{(\mathrm{a})}$ \\
\hline $\mathrm{C1C2}$ & 1.3888 & 1.3897 & 1.3901 & 1.3865 & 1.3858 & 1.3858 & $1.419^{(\mathrm{a})}$ \\
\hline $\mathrm{C} 2 \mathrm{~N}$ & 1.1761 & 1.1773 & 1.1778 & 1.1754 & 1.1754 & 1.1752 & $1.198^{(\mathrm{a})}$ \\
\hline $\mathrm{A} 1(\mathrm{HC} 1 \mathrm{C} 2)$ & 109.48 & 109.43 & 109.40 & 109.59 & 109.71 & 109.66 & $107.4^{(\mathrm{a})}$ \\
\hline$A 2(\mathrm{C} 1 \mathrm{C} 2 \mathrm{~N})$ & 172.36 & 172.35 & 172.35 & 172.39 & 172.44 & 172.41 & $171.6^{(\mathrm{a})}$ \\
\hline$A_{e}$ & 537230 & 536569 & 536177 & 539478 & 54020 & 540376 & $510262^{(\mathrm{a})}$ \\
\hline $\boldsymbol{B}_{e}$ & 11081 & 11064 & 11057 & 11105 & 11109 & 11112 & $10725^{(a)}$ \\
\hline$C_{e}$ & 10857 & 10840 & 10833 & 10881 & 10886 & 10888 & $10505^{(\mathrm{a})}$ \\
\hline$\omega_{1}\left(\mathbf{A}^{\prime}\right)$ & 3066.1 & 3064.1 & 3063.2 & 3071.3 & 3074.3 & 3072.8 & \\
\hline$\omega_{2}\left(A^{\prime}\right)$ & 2065.0 & 2062.0 & 2061.1 & 2068.5 & 2068.8 & 2067.9 & \\
\hline$\omega_{3}\left(\mathbf{A}^{\prime}\right)$ & 1057.1 & 1057.1 & 1057.1 & 1060.2 & 1060.7 & 1060.7 & \\
\hline$\omega_{4}\left(\mathbf{A}^{\prime}\right)$ & 971.7 & 973.2 & 973.5 & 974.2 & 974.5 & 974.9 & \\
\hline$\omega_{5}\left(\mathrm{~A}^{\prime}\right)$ & 293.7 & 292.9 & 292.9 & 295.7 & 295.6 & 294.6 & \\
\hline$\omega_{6}\left(\mathrm{~A}^{\prime \prime}\right)$ & 429.6 & 427.8 & 427.3 & 430.7 & 430.7 & 430.2 & \\
\hline
\end{tabular}

a) From ref. [37] at QCISD(T)/D95** level of theory. 
Table 3. Equilibrium geometries ( $\AA$, degree), equilibrium rotational constants $(\mathrm{MHz})$ and harmonic frequencies $\left(\mathrm{cm}^{-1}\right)$ of cyclic-Singlet $\mathrm{HC}_{2} \mathrm{~N}$.(see text for more details).

\begin{tabular}{|c|c|c|c|c|c|c|c|}
\hline \multirow{2}{*}{$\begin{array}{l}\text { Cyclic } \\
\text { singlet }\end{array}$} & \multicolumn{6}{|c|}{ This work } & \multirow{2}{*}{ 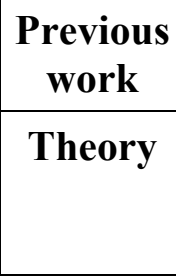 } \\
\hline & $\begin{array}{c}\text { 2-pt } \\
(t z, q z)\end{array}$ & $\begin{array}{c}2-p t \\
(q z, 5 z)\end{array}$ & $\begin{array}{c}\text { 3-pt } \\
(\mathbf{t z}, q z, 5 z)\end{array}$ & $\begin{array}{c}5 z \\
+ \text { core }+ \text { rel }\end{array}$ & $\begin{array}{c}\text { 3-pt } \\
(\mathbf{t z}, \mathbf{q z , 5 z}) \\
+ \text { core }\end{array}$ & $\begin{array}{c}\text { 3-pt } \\
(\mathbf{t z}, \mathbf{q z}, \mathbf{5 z})+ \\
\text { core+rel }\end{array}$ & \\
\hline HC1 & 1.0774 & 1.0775 & 1.0775 & 1.0762 & 1.0761 & 1.0761 & $1.083^{(\mathrm{a})}$ \\
\hline C1N2 & 1.2943 & 1.2959 & 1.2964 & 1.2937 & 1.2935 & 1.2935 & $1.314^{(\mathrm{a})}$ \\
\hline $\mathrm{N} 2 \mathrm{C} 3$ & 1.4089 & 1.4108 & 1.4116 & 1.4085 & 1.4075 & 1.4077 & $1.436^{(\mathrm{a})}$ \\
\hline $\mathrm{C1C3}$ & 1.3988 & 1.4003 & 1.4008 & 1.3974 & 1.3971 & 1.3969 & $1.422^{(\mathrm{a})}$ \\
\hline A1(HC1N2) & 137.98 & 137.95 & 137.93 & 138.02 & 138.06 & 138.04 & $137.8^{(\mathrm{a})}$ \\
\hline $\operatorname{A1}(\mathrm{C} 1 \mathrm{~N} 2 \mathrm{C3})$ & 62.15 & 62.14 & 62.13 & 62.11 & 62.13 & 62.11 & $62.09^{(\mathrm{a})}$ \\
\hline$A_{e}$ & 40835 & 40726 & 40684 & 40842 & 40883 & 40872 & $39493^{(a)}$ \\
\hline$B_{e}$ & 34647 & 34582 & 34556 & 34722 & 34732 & 34741 & $33615^{(a)}$ \\
\hline$C_{e}$ & 18744 & 18702 & 18685 & 18767 & 18779 & 18779 & $18159^{(a)}$ \\
\hline$\omega_{1}\left(\mathrm{~A}^{\prime}\right)$ & 3263.1 & 3262.4 & 3262.2 & 3268.8 & 3269.2 & 3268.5 & \\
\hline$\omega_{2}\left(\mathrm{~A}^{\prime}\right)$ & 1611.4 & 1607.3 & 1606.0 & 1613.3 & 1614.2 & 1612.9 & \\
\hline$\omega_{3}\left(\mathbf{A}^{\prime}\right)$ & 1324.3 & 1320.5 & 1319.4 & 1326.5 & 1326.2 & 1325.7 & \\
\hline$\omega_{4}\left(\mathrm{~A}^{\prime}\right)$ & 1035.9 & 1034.0 & 1033.2 & 1036.3 & 1037.9 & 1037.0 & \\
\hline$\omega_{5}\left(\mathbf{A}^{\prime}\right)$ & 845.1 & 844.8 & 844.5 & 848.4 & 850.2 & 849.6 & \\
\hline$\omega_{6}\left(A^{\prime \prime}\right)$ & 910.2 & 908.9 & 908.5 & 912.3 & 911.8 & 911.9 & \\
\hline
\end{tabular}

a) From ref [37] (QCISD(T)/D95**. 
Table 4. Rotational constants, vibrationally averaged structure ( $\AA$, degree), quartic D and sextic H centrifugal distortion constants (MHz) and vibrational fundamentals frequencies $\left(\mathrm{cm}^{-1}\right)$ computed on selected QFFs with a second order PT(S reduced Hamiltonian) of the ground state triplet $\mathrm{HC}_{2} \mathrm{~N}$.

\begin{tabular}{|c|c|c|c|c|c|c|c|c|c|}
\hline \multirow{2}{*}{$\begin{array}{c}\text { Ground } \\
\text { State } \\
\text { triplet }\end{array}$} & \multicolumn{6}{|c|}{ PT } & \multirow{2}{*}{\begin{tabular}{|c||} 
VCI \\
$3-p t$ \\
(tz,qz,5z) \\
+ core+rel \\
\end{tabular}} & \multicolumn{2}{|c|}{ Previous work } \\
\hline & $\begin{array}{c}2-p t \\
(t z, q z)\end{array}$ & $\begin{array}{c}2-p t \\
(q z, 5 z)\end{array}$ & $\begin{array}{c}\text { 3-pt } \\
(\mathbf{t z}, \mathbf{q z}, 5 \mathrm{z})\end{array}$ & $\begin{array}{c}5 z \\
+ \text { core+rel }\end{array}$ & $\begin{array}{c}\text { 3-pt } \\
(\mathbf{t z}, \mathbf{q z , 5 z}) \\
+ \text { core }\end{array}$ & $\begin{array}{c}\text { 3-pt } \\
\text { (tz,qz,5z) } \\
+ \text { core+rel }\end{array}$ & & Experiment & Theory \\
\hline $\begin{array}{l}A_{o} \\
B_{o} \\
C_{o}\end{array}$ & $\begin{array}{r}2586574 \\
11016 \\
10951\end{array}$ & $\begin{array}{r}2518363 \\
11001 \\
10935 \\
\end{array}$ & $\begin{array}{r}2496121 \\
10995 \\
10928 \\
\end{array}$ & $\begin{array}{r}2611229 \\
11037 \\
10972 \\
\end{array}$ & $\begin{array}{r}2632677 \\
11040 \\
10975 \\
\end{array}$ & $\begin{array}{r}2614091 \\
11043 \\
10979 \\
\end{array}$ & & $\begin{array}{c}4350000^{(\mathrm{b})} \\
11027^{(\mathrm{b})} \\
10986.41^{(\mathrm{a})} 10986.4^{(\mathrm{b})} \\
\end{array}$ & $10938.6^{(\mathrm{e}}$ \\
\hline $\begin{array}{c}\mathrm{HC} 1 \\
\mathrm{C} 1 \mathrm{C} 2 \\
\mathrm{C} 2 \mathrm{~N} \\
\mathrm{~A} 1(\mathrm{HC} 1 \mathrm{C} 2) \\
\mathrm{A} 2(\mathrm{C} 1 \mathrm{C} 2 \mathrm{~N})\end{array}$ & $\begin{array}{l}1.0681 \\
1.3202 \\
1.1926 \\
150.35 \\
175.77\end{array}$ & $\begin{array}{l}1.0684 \\
1.3215 \\
1.1925 \\
148.22 \\
175.70\end{array}$ & $\begin{array}{l}1.0686 \\
1.3221 \\
1.1939 \\
149.75 \\
175.71\end{array}$ & $\begin{array}{l}1.0669 \\
1.3187 \\
1.1917 \\
150.45 \\
175.80\end{array}$ & $\begin{array}{l}1.0666 \\
1.3182 \\
1.1917 \\
150.61 \\
175.84\end{array}$ & $\begin{array}{l}1.0666 \\
1.3181 \\
1.1915 \\
150.49 \\
175.81\end{array}$ & & & \\
\hline $\begin{array}{c}10^{10} H_{J} \\
H_{K} \\
10^{6} H_{J K} \\
H_{K J} \\
10^{10} h_{1} \\
10^{11} h_{2} \\
10^{11} h_{3} \\
D_{J} \\
D_{K} \\
D_{J K} \\
10^{3} d_{1} \\
10^{3} d_{2}\end{array}$ & $\begin{array}{r}-4.8164 \\
8819.37 \\
-24.083 \\
0.4180 \\
2.1872 \\
4.5841 \\
2.5398 \\
0.0042 \\
58897.4 \\
2.6957 \\
-0.0215 \\
-0.0058\end{array}$ & $\begin{array}{r}-5.1048 \\
7823.79 \\
-22.765 \\
0.3861 \\
2.1620 \\
4.6375 \\
2.5027 \\
0.0042 \\
55082.1 \\
2.6450 \\
-0.0218 \\
-0.0058\end{array}$ & $\begin{array}{r}-5.1889 \\
7509.36 \\
-22.292 \\
0.3748 \\
2.1475 \\
4.6370 \\
2.4804 \\
0.0042 \\
53865.8 \\
2.6287 \\
-0.0219 \\
-0.0058\end{array}$ & $\begin{array}{r}5.1257 \\
9170.48 \\
-24.450 \\
0.4355 \\
2.1904 \\
4.5601 \\
2.5391 \\
0.0042 \\
60321.2 \\
2.7399 \\
-0.0211 \\
-0.0058\end{array}$ & $\begin{array}{r}-5.1405 \\
9601.03 \\
-25.183 \\
0.4546 \\
2.2312 \\
4.6372 \\
2.6037 \\
0.0042 \\
61689.4 \\
2.7493 \\
-0.0213 \\
-0.0058\end{array}$ & $\begin{array}{r}-5.1787 \\
9266.62 \\
-24.780 \\
0.4433 \\
2.2248 \\
4.6559 \\
2.5960 \\
0.0042 \\
60484.5 \\
2.7397 \\
-0.0214 \\
-0.0058\end{array}$ & & $0.0041^{(b)}$ & \\
\hline $\begin{array}{c}\mathbf{v}_{1}\left(\mathbf{A}^{\prime}\right) \\
\mathbf{v}_{2}\left(\mathbf{A}^{\prime}\right) \\
\mathbf{v}_{3}\left(\mathbf{A}^{\prime}\right)^{\#} \\
\mathbf{v}_{4}\left(\mathbf{A}^{\prime}\right)^{\mathbf{a} 1} \\
\mathbf{v}_{5}\left(\mathbf{A}^{\prime}\right) \\
\mathbf{v}_{6}\left(\mathbf{A}^{\prime \prime}\right)\end{array}$ & $\begin{array}{r}3241.1 \\
1723.7 \\
1157.8 \\
292.3 \\
487.0 \\
480.3\end{array}$ & $\begin{array}{r}3236.9 \\
1725.1 \\
1154.9 \\
298.6 \\
489.5 \\
477.4\end{array}$ & $\begin{array}{r}3235.9 \\
1725.5 \\
1153.9 \\
302.1 \\
490.2 \\
476.8\end{array}$ & $\begin{array}{r}3244.6 \\
1723.2 \\
1158.8 \\
285.0 \\
488.1 \\
478.3\end{array}$ & $\begin{array}{r}3244.1 \\
1723.6 \\
1159.8 \\
274.4 \\
489.5 \\
477.4\end{array}$ & $\begin{array}{r}3243.2 \\
1722.8 \\
1159.3 \\
276.6 \\
489.0 \\
476.8\end{array}$ & $\begin{array}{r}3271.2 \\
1615.5^{\&} \\
1177.4 \\
305.8 \\
556.2 \\
561.4\end{array}$ & $\begin{array}{r}3229.0\left(^{\mathrm{c}}\right)-3247\left(^{\mathrm{d}}\right) \\
1735\left(^{\mathrm{c}}\right)-1727,1735 \\
1757\left(^{\mathrm{d}}\right) \\
1178\left(^{\mathrm{c}}\right) \\
458\left(^{\mathrm{c}}\right)-383\left(^{\mathrm{d}}\right)-365\left(^{\mathrm{d}}\right) \\
369\left(^{\mathrm{c}}\right)-187\left(^{\mathrm{d}}\right)-145\left(^{\mathrm{d}}\right)\end{array}$ & $\begin{array}{r}3246.66^{(\mathrm{e})} 3245.2^{(\mathrm{f}} \\
1733.71^{(\mathrm{e})} 1851.0^{\mathrm{f}} \\
1178.57^{(\mathrm{e})} 1113.9^{\mathrm{f}} \\
610.4^{\mathrm{f}} \\
336.2^{\mathrm{f}} \\
362.1^{\mathrm{f}}\end{array}$ \\
\hline
\end{tabular}

a)From microwave spectra ref. [23]; b) From microwave spectra ref. [17]; c) From argon matrix IR spectra ref. [16] d) From High resolution infrared spectra ref. [25];e) From ref.[59] at MR-ACPF/cc-pVQZ; f) From ref. [35] at CASSCF/DZP. ${ }^{\#} v_{3}$ affected by resonance polyad with $2 v_{4}, v_{4}+v_{5}, v_{4}, v_{5}, 2 v_{5}, 2 v_{6}, ;{ }^{a 2}$ Fermi resonance type $1 v_{4}=2 v_{5}{ }^{(\&)}$ In resonance with another state at $1992.5 \mathrm{~cm}^{-1}$. 
Table 5. Rotational constants, vibrationally averaged structure ( $\AA$, degree), quartic $\mathrm{D}$ and sextic $\mathrm{H}$ centrifugal distortion constants $(\mathrm{MHz})$ and vibrational fundamentals frequencies $\left(\mathrm{cm}^{-1}\right)$, computed on selected QFFs with a second order PT( $\mathrm{S}$ reduced Hamiltonian) of bent singlet $\mathrm{HC}_{2} \mathrm{~N}$

\begin{tabular}{|c|c|c|c|c|c|c|c|}
\hline \multirow{2}{*}{$\begin{array}{c}\text { Bent } \\
\text { Singlet }\end{array}$} & \multicolumn{6}{|c|}{ PT } & \multirow{2}{*}{\begin{tabular}{|c|} 
VCI \\
$3-p t$ \\
$(t z, q z, 5 z)$ \\
+ core+rel
\end{tabular}} \\
\hline & $\begin{array}{c}2-p t \\
(t z, q z)\end{array}$ & $\begin{array}{c}2-p t \\
(q z, 5 z)\end{array}$ & $\begin{array}{c}\text { 3-pt } \\
(\mathbf{t z}, \mathbf{q z}, 5 \mathrm{zz})\end{array}$ & $\begin{array}{c}5 z \\
+ \text { core+rel }\end{array}$ & $\begin{array}{c}\text { 3-pt } \\
(\mathrm{tz}, \mathrm{qz}, 5 \mathrm{zz}) \\
+ \text { core }\end{array}$ & $\begin{array}{c}\text { 3-pt } \\
(\mathrm{tz}, \mathrm{qz}, 5 \mathrm{z}) \\
+ \text { core+rel }\end{array}$ & \\
\hline$A_{o}$ & 540126 & 539186 & 538717 & 542306 & 543795 & 543130 & \\
\hline $\boldsymbol{B}_{o}$ & 11069 & 11052 & 11045 & 11093 & 11098 & 11099 & \\
\hline$C_{o}$ & 10833 & 10816 & 10809 & 10857 & 10861 & 10863 & \\
\hline HC1 & 1.1065 & 1.1067 & 1.1069 & 1.1406 & 1.1048 & 1.1049 & \\
\hline $\mathrm{C1C2}$ & 1.3910 & 1.3920 & 1.3924 & 1.3913 & 1.3881 & 1.3881 & \\
\hline $\mathrm{C} 2 \mathrm{~N}$ & 1.1765 & 1.1777 & 1.1782 & 1.1755 & 1.1758 & 1.1756 & \\
\hline A1(HC1C2) & 109.49 & 109.41 & 109.38 & 108.59 & 109.70 & 109.64 & \\
\hline $\mathrm{A} 2(\mathrm{C} 1 \mathrm{C} 2 \mathrm{~N})$ & 172.44 & 172.43 & 172.43 & 172.46 & 172.52 & 172.49 & \\
\hline $10^{9} H_{J}$ & -1.9452 & -1.9856 & -1.9954 & -1.9573 & -1.9578 & -1.9741 & \\
\hline$\underset{0^{6}}{H_{K}}$ & 0.4942 & 0.4802 & 0.4749 & 0.5040 & 0.5156 & 0.5083 & \\
\hline $\begin{array}{c}10^{\circ} H_{J K} \\
H_{K I}\end{array}$ & 2.4776 & 2.5099 & 2.5173 & 2.4845 & 2.4918 & 2.5012 & \\
\hline $\begin{array}{c}H_{K J} \\
10^{I I} h_{1}\end{array}$ & -0.0020 & -0.0021 & -0.0021 & -0.0021 & -0.0021 & -0.0021 & \\
\hline $10^{10} h_{2}$ & 6.7268 & 6.5112 & 6.4392 & 6.7592 & 6.8086 & 6.7709 & \\
\hline $10^{11} h_{3}$ & 1.5934 & 1.5959 & 1.5957 & 1.5935 & 1.5925 & 1.5988 & \\
\hline$D_{J}$ & 3.2622 & 3.2423 & 3.2350 & 3.2604 & 3.2545 & 3.2630 & \\
\hline$D_{K}$ & 0.0050 & 0.0050 & 0.0050 & 0.0051 & 0.0050 & 0.0051 & \\
\hline $\begin{array}{c}D_{J K} \\
10^{3} d_{l}\end{array}$ & 228.25 & 225.56 & 224.45 & 231.19 & 233.91 & 232.41 & \\
\hline $10^{3} d_{2}$ & 0.9403 & 0.9373 & 0.9360 & 0.9444 & 0.9461 & 0.9459 & \\
\hline & -0.0868 & -0.0868 & -0.0868 & -0.0867 & -0.0864 & -0.0867 & \\
\hline & -0.0214 & -0.0213 & -0.0212 & -0.0214 & -0.0213 & -0.0213 & \\
\hline$v_{1}\left(A^{\prime}\right)^{a 1}$ & 2928.8 & 2926.7 & 2925.8 & 2932.9 & 2935.3 & 2933.8 & 2934.9 \\
\hline$v_{2}\left(A^{\prime}\right)^{\#}$ & 2043.3 & 2045.1 & 2045.3 & 2048.7 & 2050.9 & 2050.7 & 2050.0 \\
\hline$v_{3}\left(A^{\prime}\right)$ & 1040.4 & 1042.5 & 1042.8 & 1044.4 & 1045.0 & 1046.9 & 1046.9 \\
\hline$v_{4}\left(A^{\prime}\right)^{a^{2}}$ & 949.1 & 956.8 & 958.3 & 953.8 & 957.5 & 958.4 & 957.0 \\
\hline$v_{5}\left(A^{\prime}\right)$ & 310.4 & 321.1 & 323.3 & 318.3 & 325.9 & 325.1 & 323.9 \\
\hline$v_{6}\left(A^{\prime \prime}\right)$ & 443.2 & 442.6 & 442.3 & 445.4 & 446.1 & 445.7 & 444.2 \\
\hline
\end{tabular}


Table 6. Rotational constants, vibrationally averaged structure ( $\AA$, degree), quartic D and sextic H centrifugal distortion constants $(\mathrm{MHz})$ and vibrational fundamentals frequencies $\left(\mathrm{cm}^{-1}\right)$ computed on selected QFFs with a second order PT( $\mathrm{s}$ reduced Hamiltonian) of cyclic singlet $\mathrm{HC}_{2} \mathrm{~N}$

\begin{tabular}{|c|c|c|c|c|c|c|c|}
\hline \multirow{2}{*}{$\begin{array}{l}\text { Cyclic } \\
\text { Singlet }\end{array}$} & \multicolumn{6}{|c|}{ PT } & \multirow{2}{*}{$\begin{array}{c}\text { VCI } \\
3-p t \\
(t z, q z, 5 z)+ \\
\text { core+rel }\end{array}$} \\
\hline & $\begin{array}{c}\text { 2-pt } \\
(\mathbf{t z}, \mathbf{q z})\end{array}$ & $\begin{array}{c}2-p t \\
(q z, 5 z)\end{array}$ & $\begin{array}{c}\text { 3-pt } \\
(\mathbf{t z}, \mathbf{q z}, 5 \mathrm{zz})\end{array}$ & $\begin{array}{c}5 z \\
+ \text { core+rel }\end{array}$ & $\begin{array}{c}\text { 3-pt } \\
(\mathbf{t z , q z , 5 z )} \\
+ \text { core }\end{array}$ & $\begin{array}{c}\text { 3-pt } \\
\text { (tz,qz,5z) } \\
+ \text { core+rel }\end{array}$ & \\
\hline$A_{o}$ & 40710 & 40599 & 40557 & 40715 & 40755 & 40744 & \\
\hline $\boldsymbol{B}_{o}$ & 34414 & 34347 & 34322 & 34489 & 34497 & 34505 & \\
\hline & 18584 & 18541 & 18525 & 18607 & 18618 & 18618 & \\
\hline HC1 & 1.0798 & 1.0799 & 1.0800 & 1.0787 & 1.0786 & 1.0786 & \\
\hline C1N2 & 1.3005 & 1.3020 & 1.3026 & 1.2998 & 1.2997 & 1.2996 & \\
\hline N2C3 & 1.4152 & 1.4171 & 1.4179 & 1.4148 & 1.4138 & 1.4141 & \\
\hline $\mathrm{C1C3}$ & 1.4066 & 1.4082 & 1.4087 & 1.4052 & 1.4050 & 1.4047 & \\
\hline $\mathrm{A} 1(\mathrm{HC} 1 \mathrm{~N} 2)$ & 137.87 & 137.84 & 137.84 & 137.93 & 137.97 & 137.94 & \\
\hline $\mathrm{A} 2(\mathrm{C} 1 \mathrm{~N} 2 \mathrm{C} 3)$ & 62.22 & 62.21 & 62.20 & 62.18 & 62.20 & 62.18 & \\
\hline $10^{7} H_{J}$ & -2.8738 & -2.9026 & -2.9074 & -2.8896 & -2.9053 & -2.9132 & \\
\hline $10^{6} H_{K}$ & 18.495 & 18.533 & 18.596 & 18.619 & 18.153 & 18.336 & \\
\hline $\begin{array}{l}10^{6} H_{J K} \\
10^{6} H_{K I}\end{array}$ & 6.5936 & 6.6283 & 6.6488 & 6.6516 & 6.5510 & 6.6001 & \\
\hline $10^{10} h_{1}$ & -21.723 & -21.796 & -21.876 & -21.910 & -21.399 & -21.605 & \\
\hline $10^{10} h_{2}$ & 801.93 & 792.82 & 793.75 & 810.24 & 781.45 & 789.14 & \\
\hline $10^{10} h_{3}$ & 1886.4 & 1886.4 & 1885.4 & 1891.1 & 1892.1 & 1895.6 & \\
\hline$D_{J}$ & -347.91 & -353.36 & -357.60 & -359.28 & -337.83 & -345.77 & \\
\hline $\begin{array}{c}D_{K} \\
D_{K K}\end{array}$ & 0.0471 & 0.0469 & 0.0469 & 0.0470 & 0.0472 & 0.0472 & \\
\hline $\begin{array}{c}D_{J K} \\
d_{l}\end{array}$ & 0.0904 & 0.0885 & 0.0876 & 0.0882 & 0.0902 & 0.0893 & \\
\hline$d_{2}$ & 0.0954 & 0.0961 & 0.0966 & 0.0970 & 0.0949 & 0.0960 & \\
\hline & -0.0263 & -0.0263 & -0.0263 & -0.0264 & -0.0264 & -0.0264 & \\
\hline & -0.0090 & -0.0090 & -0.0090 & -0.0090 & -0.0090 & -0.0090 & \\
\hline$v_{1}\left(A^{\prime}\right)^{\mathbf{a} 1}$ & 3122.7 & 3118.6 & 3117.4 & 3126.1 & 3125.8 & 3124.7 & 3126.0 \\
\hline$v_{2}\left(A^{\prime}\right)^{\mathbf{a} 2}$ & 1571.1 & 1567.0 & 1565.7 & 1572.8 & 1573.9 & 1572.5 & 1576.5 \\
\hline$v_{3}\left(A^{\prime}\right)$ & 1292.0 & 1288.6 & 1287.6 & 1294.4 & 1294.1 & 1293.6 & 1294.1 \\
\hline$v_{4}\left(A^{\prime}\right)$ & 1012.5 & 1012.0 & 1011.6 & 1013.7 & 1015.9 & 1015.1 & 1014.4 \\
\hline$v_{5}\left(A^{\prime}\right)$ & 823.9 & 821.3 & 820.4 & 825.1 & 825.9 & 824.9 & 832.4 \\
\hline$v_{6}\left(A^{\prime \prime}\right)$ & 899.6 & 894.5 & 893.3 & 898.8 & 896.4 & 896.0 & 901.3 \\
\hline
\end{tabular}

${ }^{\mathrm{al}}$ Fermi resonance type $1 v_{1}=2 v_{2}$;

${ }^{\mathrm{a} 2}$ Fermi resonance type $1 v_{2}=2 v_{5}$. 
Table 7. Anharmonic constants $\left(\mathrm{cm}^{-1}\right) X_{i j}$ using second order PT of ground state triplet $\mathrm{HC}_{2} \mathrm{~N}$

\begin{tabular}{|c|c|c|c|c|c|c|}
\hline \multirow[t]{2}{*}{$X_{i j}$} & \multicolumn{6}{|c|}{ 3-pt(tz,qz,5z)+core+rel } \\
\hline & 1 & 2 & 3 & 4 & 5 & 6 \\
\hline 1 & -61.465 & & & & & \\
\hline 2 & 13.944 & -50.113 & & & & \\
\hline 3 & -8.108 & $14.163^{*}$ & -6.800 & & & \\
\hline 4 & 31.217 & $-100.021^{*}$ & $29.339 *$ & $-94.294 *$ & & \\
\hline 5 & -1.368 & -12.715 & $4.792 *$ & $-27.770 *$ & $-1.187^{*}$ & \\
\hline 6 & -1.436 & -7.656 & 6.595 & 18.391 & 86.801 & -1.644 \\
\hline
\end{tabular}

$\left.{ }^{*}\right)$ Constants are affected by Fermi resonance

Table 8. Anharmonic constants $\left(\mathrm{cm}^{-1}\right) X_{i j}$ using second order PT of bent singlet $\mathrm{HC}_{2} \mathrm{~N}$

\begin{tabular}{|c|c|c|c|c|c|c|}
\hline \multirow{2}{*}{$X_{i j}$} & \multicolumn{6}{|c|}{ 3-pt(tz,qz,5z)+core+rel } \\
\hline & 1 & 2 & 3 & 4 & 5 & 6 \\
\hline 1 & -66.238 & & & & & \\
\hline 2 & $2.655^{*}$ & -14.469 & & & & \\
\hline 3 & -14.622 & $-3.506^{*}$ & $-2.534^{*}$ & & & \\
\hline 4 & $4.766 *$ & $-7.103 *$ & $-14.900 *$ & $-9.029 *$ & & \\
\hline 5 & -1.322 & -4.844 & 13.485 & 17.358 & -0.310 & \\
\hline 6 & -3.616 & -3.242 & 2.222 & $1.072 *$ & 37.720 & $-0.810 *$ \\
\hline
\end{tabular}

*)Constants are affected by Fermi resonance 
Table 9. Anharmonic constants $X_{i j}\left(\mathrm{~cm}^{-1}\right)$ using second order PT of cyclic singlet $\mathrm{HC}_{2} \mathrm{~N}$

\begin{tabular}{crccccc}
\hline$X_{i j}$ & \multicolumn{6}{c}{ 3-pt(tz,qz,5z)+core+rel } \\
\cline { 2 - 7 } & \multicolumn{1}{c}{$\boldsymbol{1}$} & $\mathbf{2}$ & $\mathbf{3}$ & $\mathbf{4}$ & $\mathbf{5}$ & $\mathbf{6}$ \\
\hline $\mathbf{1}$ & -59.814 & & & & & \\
$\mathbf{2}$ & $-0.187^{*}$ & $-6.770^{*}$ & & & & \\
$\mathbf{3}$ & 6.009 & -13.684 & -9.301 & & & \\
$\mathbf{4}$ & -7.839 & -11.05 & -4.418 & -6.014 & & \\
$\mathbf{5}$ & -12.097 & $-8.185^{*}$ & -12.693 & 0.432 & $-4.278^{*}$ & \\
$\mathbf{6}$ & -18.906 & -4.260 & -2.235 & 3.292 & 0.186 & -2.471 \\
\hline \hline *)Constants are affected by Fermi resonance
\end{tabular}

*)Constants are affected by Fermi resonance 
Table 10. Force constants of ground state triplet $\mathrm{HC}_{2} \mathrm{~N}$

\begin{tabular}{|c|c|c|c|c|c|c|c|c|c|}
\hline \multicolumn{10}{|c|}{$3-p t(t z, q z, 5 z)+$ core + rel } \\
\hline \multicolumn{2}{|c|}{ Quadratic } & \multicolumn{2}{|c|}{ Cubic } & \multicolumn{6}{|c|}{ Quartic } \\
\hline$F_{11}$ & 6.099718 & $F_{111}$ & -35.0216 & $F_{1111}$ & 178.13 & $F_{5321}$ & -0.08 & $F_{6651}$ & 0.27 \\
\hline$F_{21}$ & -0.103938 & $F_{211}$ & 0.0314 & $F_{2111}$ & -0.66 & $F_{5322}$ & -0.31 & $F_{6652}$ & 0.06 \\
\hline$F_{22}$ & 6.869360 & $F_{221}$ & -0.0878 & $F_{2211}$ & -0.50 & $F_{5331}$ & -0.03 & $F_{6653}$ & -0.24 \\
\hline$F_{31}$ & -0.020148 & $F_{222}$ & -39.8088 & $F_{2221}$ & -0.17 & $F_{5332}$ & -0.21 & $F_{6654}$ & -0.05 \\
\hline$F_{32}$ & 2.547680 & $F_{311}$ & 0.1146 & $F_{2222}$ & 208.28 & $F_{5333}$ & 0.63 & $F_{6655}$ & 0.54 \\
\hline$F_{33}$ & 13.804232 & $F_{321}$ & -0.0750 & $F_{3111}$ & 0.10 & $F_{5411}$ & 0.15 & $F_{6666}$ & 1.99 \\
\hline$F_{41}$ & 0.107727 & $F_{322}$ & -12.1467 & $F_{3211}$ & -0.50 & $F_{5421}$ & 0.09 & & \\
\hline$F_{42}$ & 0.497186 & $F_{331}$ & 0.0586 & $F_{3221}$ & 0.33 & $F_{5422}$ & -0.17 & & \\
\hline$F_{43}$ & -0.194265 & $F_{332}$ & 6.7619 & $F_{3222}$ & 51.85 & $F_{5431}$ & -0.07 & & \\
\hline$F_{44}$ & 0.198258 & $F_{333}$ & -108.4164 & $F_{3311}$ & 0.42 & $F_{5432}$ & 0.15 & & \\
\hline$F_{51}$ & 0.09182 & $F_{411}$ & 0.0745 & $F_{3321}$ & -0.15 & $F_{5433}$ & 0.06 & & \\
\hline$F_{52}$ & 0.042316 & $F_{421}$ & -0.1607 & $F_{3322}$ & -44.35 & $F_{5441}$ & 0.13 & & \\
\hline$F_{53}$ & 0.099894 & $F_{422}$ & -1.1752 & $F_{3331}$ & 0.35 & $F_{5442}$ & -0.11 & & \\
\hline$F_{54}$ & 0.003399 & $F_{431}$ & -0.0122 & $F_{3332}$ & 33.10 & $F_{5443}$ & -0.07 & & \\
\hline$F_{55}$ & 0.370815 & $F_{432}$ & 0.9678 & $F_{3333}$ & 545.73 & $F_{5444}$ & -0.06 & & \\
\hline \multirow[t]{25}{*}{$F_{66}$} & 0.384813 & $F_{433}$ & -0.6078 & $F_{4111}$ & -0.36 & $F_{5511}$ & -0.02 & & \\
\hline & & $F_{441}$ & -0.1227 & $F_{4211}$ & -0.04 & $F_{5521}$ & 0.09 & & \\
\hline & & $F_{442}$ & -0.0570 & $F_{4221}$ & -0.08 & $F_{5522}$ & 1.09 & & \\
\hline & & $F_{443}$ & -0.1822 & $F_{4222}$ & 3.46 & $F_{5531}$ & 0.17 & & \\
\hline & & $F_{444}$ & -0.7923 & $F_{4311}$ & 0.17 & $F_{5532}$ & 0.01 & & \\
\hline & & $F_{511}$ & 0.0035 & $F_{4321}$ & 0.27 & $F_{5533}$ & 1.02 & & \\
\hline & & $F_{521}$ & -0.0223 & $F_{4322}$ & -3.85 & $F_{5541}$ & 0.15 & & \\
\hline & & $F_{522}$ & -0.2417 & $F_{4331}$ & -0.05 & $F_{5542}$ & -0.04 & & \\
\hline & & $F_{531}$ & -0.0195 & $F_{4332}$ & 3.04 & $F_{5543}$ & -0.36 & & \\
\hline & & $F_{532}$ & -0.1100 & $F_{4333}$ & -2.34 & $F_{5544}$ & 0.12 & & \\
\hline & & $F_{533}$ & 0.1245 & $F_{4411}$ & -0.05 & $F_{5551}$ & -0.10 & & \\
\hline & & $F_{541}$ & 0.0004 & $F_{4421}$ & 0.65 & $F_{5552}$ & 0.57 & & \\
\hline & & $F_{542}$ & 0.0660 & $F_{4422}$ & 0.78 & $F_{5553}$ & 0.25 & & \\
\hline & & $F_{543}$ & -0.0936 & $F_{4431}$ & -0.09 & $F_{5554}$ & 0.18 & & \\
\hline & & $F_{544}$ & -0.1878 & $F_{4432}$ & 0.23 & $F_{5555}$ & 2.49 & & \\
\hline & & $F_{551}$ & -0.0250 & $F_{4433}$ & -0.56 & $F_{6611}$ & -0.16 & & \\
\hline & & $F_{552}$ & -0.5696 & $F_{4441}$ & 0.08 & $F_{6621}$ & 0.09 & & \\
\hline & & $F_{553}$ & -0.6664 & $F_{4442}$ & -1.83 & $F_{6622}$ & 0.66 & & \\
\hline & & $F_{554}$ & 0.0543 & $F_{4443}$ & 1.22 & $F_{6631}$ & -0.04 & & \\
\hline & & $F_{555}$ & -0.1372 & $F_{4444}$ & 0.12 & $F_{6632}$ & 2.00 & & \\
\hline & & $F_{661}$ & -0.0167 & $F_{5111}$ & -0.12 & $F_{6633}$ & 0.43 & & \\
\hline & & $F_{662}$ & -0.5635 & $F_{5211}$ & -0.03 & $F_{6641}$ & 0.10 & & \\
\hline & & $F_{663}$ & -0.7123 & $F_{5221}$ & -0.12 & $F_{6642}$ & 0.08 & & \\
\hline & & $F_{664}$ & 0.0042 & $F_{5222}$ & 1.45 & $F_{6643}$ & 0.09 & & \\
\hline & & $F_{665}$ & -0.0456 & $F_{5311}$ & -0.20 & $F_{6644}$ & -0.25 & & \\
\hline
\end{tabular}

* Units of the force constants are $\mathrm{mdyn} / \AA^{n} \mathrm{rad}^{m}$ appropiate for an energy unit of mdyn $\AA$ (1 mdyn $\left.\AA=1 \mathrm{aJ}\right)$. 
Table 11. Force constants of bent singlet $\mathrm{HC}_{2} \mathrm{~N}$

\begin{tabular}{|c|c|c|c|c|c|c|c|c|c|}
\hline \multicolumn{10}{|c|}{$3-p t(t z, q z, 5 z)+$ core + rel } \\
\hline \multicolumn{2}{|c|}{ Quadratic } & \multicolumn{2}{|c|}{ Cubic } & \multicolumn{6}{|c|}{ Quartic } \\
\hline$F_{11}$ & 5.177931 & $F_{111}$ & -30.3037 & $F_{1111}$ & 153.39 & $F_{5321}$ & 0.03 & $F_{6651}$ & -0.02 \\
\hline$F_{21}$ & -0.078059 & $F_{211}$ & -0.0546 & $F_{2111}$ & -0.42 & $F_{5322}$ & -0.73 & $F_{6652}$ & 0.22 \\
\hline$F_{22}$ & 5.686484 & $F_{221}$ & -0.1827 & $F_{2211}$ & 0.12 & $F_{5331}$ & 0.004 & $F_{6653}$ & 0.04 \\
\hline$F_{31}$ & 0.016299 & $F_{222}$ & -34.8266 & $F_{2221}$ & -0.41 & $F_{5332}$ & 0.34 & $F_{6654}$ & 0.75 \\
\hline$F_{32}$ & 1.248974 & $F_{311}$ & 0.0800 & $F_{2222}$ & 189.14 & $F_{5333}$ & -0.20 & $F_{6655}$ & 1.19 \\
\hline$F_{33}$ & 15.696256 & $F_{321}$ & -0.1485 & $F_{3111}$ & -0.42 & $F_{5411}$ & -0.02 & $F_{6666}$ & 1.29 \\
\hline$F_{41}$ & 0.256731 & $F_{322}$ & -4.6015 & $F_{3211}$ & -0.47 & $F_{5421}$ & 0.27 & & \\
\hline$F_{42}$ & 0.598469 & $F_{331}$ & 0.0460 & $F_{3221}$ & 0.18 & $F_{5422}$ & -0.45 & & \\
\hline$F_{43}$ & -0.096386 & $F_{332}$ & 1.0410 & $F_{3222}$ & 4.45 & $F_{5431}$ & 0.04 & & \\
\hline$F_{44}$ & 0.618229 & $F_{333}$ & -110.1983 & $F_{3311}$ & 0.28 & $F_{5432}$ & 0.16 & & \\
\hline$F_{51}$ & 0.044490 & $F_{411}$ & -0.0473 & $F_{3321}$ & -0.12 & $F_{5433}$ & 0.08 & & \\
\hline$F_{52}$ & 0.092149 & $F_{421}$ & -0.4747 & $F_{3322}$ & 2.91 & $F_{5441}$ & 0.18 & & \\
\hline$F_{53}$ & 0.127001 & $F_{422}$ & -0.9156 & $F_{3331}$ & -0.02 & $F_{5442}$ & 0.33 & & \\
\hline$F_{54}$ & 0.090590 & $F_{431}$ & 0.0451 & $F_{3332}$ & -7.13 & $F_{5443}$ & 0.02 & & \\
\hline$F_{55}$ & 0.454490 & $F_{432}$ & 0.5959 & $F_{3333}$ & 599.39 & $F_{5444}$ & -0.08 & & \\
\hline \multirow[t]{25}{*}{$F_{66}$} & 0.176844 & $F_{433}$ & -0.3576 & $F_{4111}$ & -1.14 & $F_{5511}$ & -0.13 & & \\
\hline & & $F_{441}$ & -0.3082 & $F_{4211}$ & -0.04 & $F_{5521}$ & 0.09 & & \\
\hline & & $F_{442}$ & 0.3516 & $F_{4221}$ & -0.36 & $F_{5522}$ & 1.82 & & \\
\hline & & $F_{443}$ & -0.5044 & $F_{4222}$ & -0.33 & $F_{5531}$ & 0.04 & & \\
\hline & & $F_{444}$ & -0.8951 & $F_{4311}$ & -0.00 & $F_{5532}$ & 0.30 & & \\
\hline & & $F_{511}$ & -0.0119 & $F_{4321}$ & -0.10 & $F_{5533}$ & 0.47 & & \\
\hline & & $F_{521}$ & -0.1458 & $F_{4322}$ & -1.32 & $F_{5541}$ & -0.10 & & \\
\hline & & $F_{522}$ & -0.5268 & $F_{4331}$ & 0.09 & $F_{5542}$ & 0.01 & & \\
\hline & & $F_{531}$ & -0.0478 & $F_{4332}$ & 0.61 & $F_{5543}$ & -0.08 & & \\
\hline & & $F_{532}$ & -0.1084 & $F_{4333}$ & -0.24 & $F_{5544}$ & 0.37 & & \\
\hline & & $F_{533}$ & -0.0208 & $F_{4411}$ & 0.09 & $F_{5551}$ & 0.13 & & \\
\hline & & $F_{541}$ & -0.0398 & $F_{4421}$ & 0.75 & $F_{5552}$ & 0.51 & & \\
\hline & & $F_{542}$ & 0.0398 & $F_{4422}$ & -1.68 & $F_{5553}$ & 0.14 & & \\
\hline & & $F_{543}$ & -0.0683 & $F_{4431}$ & -0.16 & $F_{5554}$ & -0.03 & & \\
\hline & & $F_{544}$ & -0.2001 & $F_{4432}$ & 1.38 & $F_{5555}$ & 2.73 & & \\
\hline & & $F_{551}$ & -0.0452 & $F_{4433}$ & -0.75 & $F_{6611}$ & 0.12 & & \\
\hline & & $F_{552}$ & -0.8930 & $F_{4441}$ & 0.79 & $F_{6621}$ & 0.03 & & \\
\hline & & $F_{553}$ & -0.5875 & $F_{4442}$ & -0.44 & $F_{6622}$ & 0.55 & & \\
\hline & & $F_{554}$ & 0.0273 & $F_{4443}$ & 0.54 & $F_{6631}$ & -0.06 & & \\
\hline & & $F_{555}$ & -0.2939 & $F_{4444}$ & -0.39 & $F_{6632}$ & -0.13 & & \\
\hline & & $F_{661}$ & -0.0411 & $F_{5111}$ & -0.19 & $F_{6633}$ & 1.15 & & \\
\hline & & $F_{662}$ & -0.1594 & $F_{5211}$ & -0.04 & $F_{6641}$ & -0.92 & & \\
\hline & & $F_{663}$ & -0.4751 & $F_{5221}$ & 0.31 & $F_{6642}$ & -0.14 & & \\
\hline & & $F_{664}$ & 0.0355 & $F_{5222}$ & 1.74 & $F_{6643}$ & -0.17 & & \\
\hline & & $F_{665}$ & -0.1267 & $F_{5311}$ & 0.01 & $F_{6644}$ & 0.91 & & \\
\hline
\end{tabular}

*Units of the force constants are $\mathrm{mdyn} / \AA^{n} \mathrm{rad}^{m}$ appropiate for an energy unit of mdyn $\AA$ (1 mdyn $\left.\AA=1 \mathrm{aJ}\right)$. 
Table 12. Force constants of cyclic singlet $\mathrm{HC}_{2} \mathrm{~N}$

\begin{tabular}{|c|c|c|c|c|c|c|c|c|c|}
\hline \multicolumn{10}{|c|}{ 3-pt(tz,qz,5z)+core+rel} \\
\hline \multicolumn{2}{|c|}{ Quadratic } & \multicolumn{2}{|c|}{ Cubic } & \multicolumn{6}{|c|}{ Quartic } \\
\hline$F_{11}$ & 5.794836 & $F_{111}$ & -33.6249 & $F_{1111}$ & 172.40 & $F_{5321}$ & -0.66 & $F_{6651}$ & -0.28 \\
\hline$F_{21}$ & 0.089307 & $F_{211}$ & 0.3365 & $F_{2111}$ & -0.88 & $F_{5322}$ & 15.21 & $F_{6652}$ & -0.24 \\
\hline$F_{22}$ & 10.266993 & $F_{221}$ & -0.5971 & $F_{2211}$ & -1.18 & $F_{5331}$ & -0.11 & $F_{6653}$ & -0.74 \\
\hline$F_{31}$ & -0.068733 & $F_{222}$ & -59.4398 & $F_{2221}$ & 2.45 & $F_{5332}$ & 27.33 & $F_{6654}$ & 0.78 \\
\hline$F_{32}$ & 0.788188 & $F_{311}$ & 0.0216 & $F_{2222}$ & 294.28 & $F_{5333}$ & -3.57 & $F_{6655}$ & 1.40 \\
\hline$F_{33}$ & 7.615518 & $F_{321}$ & -0.1056 & $F_{3111}$ & -0.52 & $F_{5411}$ & -0.25 & $F_{6666}$ & 1.95 \\
\hline$F_{41}$ & 0.029753 & $F_{322}$ & -3.3018 & $F_{3211}$ & 0.21 & $F_{5421}$ & 0.10 & & \\
\hline$F_{42}$ & 0.101387 & $F_{331}$ & -0.0115 & $F_{3221}$ & -0.06 & $F_{5422}$ & -1.12 & & \\
\hline$F_{43}$ & 0.072597 & $F_{332}$ & -2.7149 & $F_{3222}$ & 12.25 & $F_{5431}$ & -0.01 & & \\
\hline$F_{44}$ & 0.546874 & $F_{333}$ & -39.9175 & $F_{3311}$ & -0.56 & $F_{5432}$ & -0.31 & & \\
\hline$F_{51}$ & -0.117645 & $F_{411}$ & 0.0292 & $F_{3321}$ & -0.27 & $F_{5433}$ & 1.81 & & \\
\hline$F_{52}$ & 2.625797 & $F_{421}$ & -0.3208 & $F_{3322}$ & 3.25 & $F_{5441}$ & -0.13 & & \\
\hline$F_{53}$ & 2.724999 & $F_{422}$ & -0.0491 & $F_{3331}$ & 1.24 & $F_{5442}$ & 0.57 & & \\
\hline$F_{54}$ & 0.023056 & $F_{431}$ & 0.2592 & $F_{3332}$ & 15.47 & $F_{5443}$ & -1.12 & & \\
\hline$F_{55}$ & 5.707030 & $F_{432}$ & 0.0567 & $F_{3333}$ & 170.01 & $F_{5444}$ & 0.35 & & \\
\hline \multirow{25}{*}{$F_{66}$} & 0.425536 & $F_{433}$ & -0.2563 & $F_{4111}$ & -0.20 & $F_{5511}$ & -0.38 & & \\
\hline & & $F_{441}$ & -0.1263 & $F_{4211}$ & -0.23 & $F_{5521}$ & 0.60 & & \\
\hline & & $F_{442}$ & -0.7306 & $F_{4221}$ & 0.76 & $F_{5522}$ & 0.47 & & \\
\hline & & $F_{443}$ & -0.2954 & $F_{4222}$ & 1.23 & $F_{5531}$ & -0.04 & & \\
\hline & & $F_{444}$ & -0.2603 & $F_{4311}$ & 0.13 & $F_{5532}$ & 53.50 & & \\
\hline & & $F_{511}$ & -0.1860 & $F_{4321}$ & 0.07 & $F_{5533}$ & 33.17 & & \\
\hline & & $F_{521}$ & 0.0620 & $F_{4322}$ & -1.92 & $F_{5541}$ & 0.14 & & \\
\hline & & $F_{522}$ & -5.8720 & $F_{4331}$ & -0.46 & $F_{5542}$ & -0.99 & & \\
\hline & & $F_{531}$ & 0.2778 & $F_{4332}$ & 1.52 & $F_{5543}$ & 0.39 & & \\
\hline & & $F_{532}$ & -6.0349 & $F_{4333}$ & -0.98 & $F_{5544}$ & -1.90 & & \\
\hline & & $F_{533}$ & -8.5677 & $F_{4411}$ & -0.38 & $F_{5551}$ & 0.50 & & \\
\hline & & $F_{541}$ & -0.0755 & $F_{4421}$ & 0.14 & $F_{5552}$ & 77.33 & & \\
\hline & & $F_{542}$ & 0.2102 & $F_{4422}$ & 0.85 & $F_{5553}$ & 125.07 & & \\
\hline & & $F_{543}$ & -0.6873 & $F_{4431}$ & 0.21 & $F_{5554}$ & -4.50 & & \\
\hline & & $F_{544}$ & 0.9470 & $F_{4432}$ & 0.22 & $F_{5555}$ & 345.77 & & \\
\hline & & $F_{551}$ & 0.0091 & $F_{4433}$ & 0.15 & $F_{6611}$ & -0.24 & & \\
\hline & & $F_{552}$ & -15.3923 & $F_{4441}$ & 0.10 & $F_{6621}$ & -0.13 & & \\
\hline & & $F_{553}$ & -20.7043 & $F_{4442}$ & 1.24 & $F_{6622}$ & -0.19 & & \\
\hline & & $F_{554}$ & 1.2424 & $F_{4443}$ & -0.87 & $F_{6631}$ & 0.52 & & \\
\hline & & $F_{555}$ & -46.7521 & $F_{4444}$ & -0.09 & $F_{6632}$ & 0.35 & & \\
\hline & & $F_{661}$ & -0.1333 & $F_{5111}$ & 0.47 & $F_{6633}$ & -0.39 & & \\
\hline & & $F_{662}$ & -0.2581 & $F_{5211}$ & -0.19 & $F_{6641}$ & -0.04 & & \\
\hline & & $F_{663}$ & -0.2352 & $F_{5221}$ & 0.70 & $F_{6642}$ & -0.63 & & \\
\hline & & $F_{664}$ & 0.5859 & $F_{5222}$ & -11.44 & $F_{6643}$ & -0.11 & & \\
\hline & & $F_{665}$ & -0.0324 & $F_{5311}$ & 0.34 & $F_{6644}$ & 1.71 & & \\
\hline
\end{tabular}

* Units of the force constants are $\mathrm{mdyn} / \AA^{n} \mathrm{rad}^{m}$ appropiate for an energy unit of mdyn $\AA$ (1 mdyn $\left.\AA=1 \mathrm{aJ}\right)$. 
Table 13. Alpha-rovibrational constants ( $\mathrm{MHz}$ ) using second order $\mathrm{PT}$ of $\mathrm{HC}_{2} \mathrm{~N}$ Isomers

\begin{tabular}{|c|c|c|c|}
\hline & $\begin{array}{c}\text { Bent } \\
\text { Triplet }\end{array}$ & $\begin{array}{c}\text { Bent } \\
\text { Singlet }\end{array}$ & $\begin{array}{l}\text { Cyclic } \\
\text { Singlet }\end{array}$ \\
\hline$\alpha_{1 \mathrm{~A}}$ & -202538.7 & 26548.6 & 43.8 \\
\hline $\boldsymbol{\alpha}_{2 \mathrm{~A}}$ & -300037.4 & -2561.8 & 195.1 \\
\hline$\alpha_{3 A}$ & -118621.8 & -8510.0 & -289.9 \\
\hline $\boldsymbol{\alpha}_{4 \mathrm{~A}}$ & $-1561849.3^{*}$ & -32431.9 & $316.4^{*}$ \\
\hline \multirow{2}{*}{$\boldsymbol{\alpha}_{6 \mathrm{~A}}$} & $-310272.7 *$ & $14143.9^{*}$ & $-182.7 *$ \\
\hline & $-4008.5 *$ & $-2697.1 *$ & $174.0 *$ \\
\hline $\boldsymbol{\alpha}_{1 \mathrm{~B}}$ & -24.4 & 14.7 & 177.1 \\
\hline $\boldsymbol{\alpha}_{2 \mathrm{~B}}$ & -50.5 & 59.9 & 92.2 \\
\hline $\boldsymbol{\alpha}_{3 \mathrm{~B}}$ & -47.6 & 15.3 & 232.4 \\
\hline $\boldsymbol{\alpha}_{4 \mathrm{~B}}$ & 10.9 & 25.2 & -226.4 \\
\hline $\boldsymbol{\alpha}_{5 \mathrm{~B}}$ & 46.6 & -48.7 & 99.4 \\
\hline $\boldsymbol{\alpha}_{6 \mathrm{~B}}$ & 22.0 & -42.0 & 95.6 \\
\hline$\alpha_{1 C}$ & -32.4 & 23.8 & 60.2 \\
\hline $\boldsymbol{\alpha}_{2 \mathrm{C}}$ & -37.3 & 55.9 & 59.0 \\
\hline $\boldsymbol{\alpha}_{3 \mathrm{C}}$ & -51.8 & 12.8 & 2.7 \\
\hline $\boldsymbol{\alpha}_{4 \mathrm{C}}$ & $26.0 *$ & 45.9 & $149.5^{*}$ \\
\hline $\boldsymbol{\alpha}_{s \mathbf{C}}$ & $21.2^{*}$ & -76.3 & $72.9 *$ \\
\hline $\boldsymbol{\alpha}_{6 \mathrm{C}}$ & 45.7 & -12.6 & -21.7 \\
\hline
\end{tabular}


Table 14. Relative energies (in Kcal $/ \mathrm{mol}$ ) and dipole moments ( $\mu$, in Debye). These energies are given with respect to the $\mathrm{X}^{3} A^{\prime \prime}$ ground state triplet structure.

\begin{tabular}{lccc}
\hline \multicolumn{1}{c}{$\mathbf{H C}_{2} \mathbf{N}$} & $\Delta \mathbf{E}^{(\mathbf{1})}$ & $\Delta \mathbf{E}^{(\mathbf{2})}$ & $\boldsymbol{\mu}^{(\mathbf{3})}$ \\
\hline $\begin{array}{l}\text { Ground State } \\
\text { triplet }\end{array}$ & 0.0 & 0.0 & 3.05 \\
$\begin{array}{l}\text { Cyclic singlet } \\
\text { Bent singlet }\end{array}$ & 5.7 & 7.8 & 3.06 \\
$\begin{array}{l}\text { came from the best ab intio } \text { QFFs, 3-pt(tz,qz,5z)+core+rel. } \\
\text { anharmonic Zero-point energies corrections. }\end{array}$ \\
moments computed at $\mathrm{CCSD}(\mathrm{T}) / \mathrm{cc}-\mathrm{pVQZ}$ level of theory.
\end{tabular}

